\title{
Power Enhancement under Partial Shading Condition Using a Two-Step Optimal PV Array Reconfiguration
}

\author{
Mohamad Hossien Nahidan, Mehdi Niroomand (D), and Behzad Mirzaeian Dehkordi \\ Department of Electrical Engineering, University of Isfahan, Isfahan, Iran \\ Correspondence should be addressed to Mehdi Niroomand; mehdi_niroomand@yahoo.com
}

Received 14 August 2020; Revised 15 November 2020; Accepted 2 January 2021; Published 13 January 2021

Academic Editor: Ahmad Umar

Copyright (c) 2021 Mohamad Hossien Nahidan et al. This is an open access article distributed under the Creative Commons Attribution License, which permits unrestricted use, distribution, and reproduction in any medium, provided the original work is properly cited.

\begin{abstract}
Under partial shading conditions, photovoltaic (PV) arrays are subjected to different irradiance levels caused by nonuniform shading. As a result, a mismatch between the modules, a reduction in the power generated, and the hotspot phenomenon will be observed. One method to reduce mismatch losses is to reconfigure the total-cross-tied (TCT) array in dynamic and static forms, where improved performance can be achieved through more efficient shading distribution thanks to increased dimensions. However, the increase in dimensions leads to the complexity of wiring and installation in static reconfiguration and the large number of switches and sensors required in dynamic reconfiguration. To rectify these problems, a two-step method is proposed in this paper. In the first step, the modules inside the PV array are divided into subarrays with wiring in static reconfiguration, rather than being wired as large-scale PV arrays. In the second step, an algorithm is developed for dynamic reconfiguration. The introduced algorithm searches for all possible connections and finally identifies the most optimal solution. As an advantage, this algorithm employs only the short-circuit current values of the subarray rows, which reduces the number of switches and sensors required in comparison to dynamic reconfiguration. Under 8 different partial shading patterns, simulations are conducted and results confirm that the proposed method outperforms the TCT array and statically modified TCT array in terms of power and mismatch losses. Among these, the highest power improvement is obtained with regard to the TCT array and statically modified TCT array under the fourth and eighth shading patterns, respectively.
\end{abstract}

\section{Introduction}

Solar energy is considered to be the most popular renewable energy around the world and is capable of converting into different types of energy. Every second, approximately 4.2 million tons of solar mass is converted to different types of energy, and because the sun weighs 333 times the weight of the earth, solar energy can meet energy requirements for the next 5 billion years [1].

To meet the load power demands, the PV panels are typically connected in parallel or series. However, the power generated by the PV array is drastically reduced when one or several PV panels are exposed to partial shading, which is led by the shadows of trees, buildings, and poles and even the movement of clouds in large-scale PV systems [2-5]. Par- tial shading, which is actually a consequence of nonuniform irradiation conditions, creates multiple peaks on the $P-V$ curve and causes output power losses [6]. The shading pattern, location of shaded modules, and array configuration are among the most effective parameters on these losses.

$\mathrm{PV}$ arrays with various interconnection schemes such as series-parallel (SP), total-cross-tied (TCT), and bridge link (BL) have been presented (see Figure 1). The presented schemes have been investigated in terms of maximum power and fill factor (FF) under different partial shading patterns. The results indicate that PV arrays using the TCT interconnection scheme outperform others [7, 8].

For large-scale PV arrays, a solution is to first divide them into subarrays with TCT wiring and then arrange the subarrays into a TCT array [9]. To verify this scheme, a 


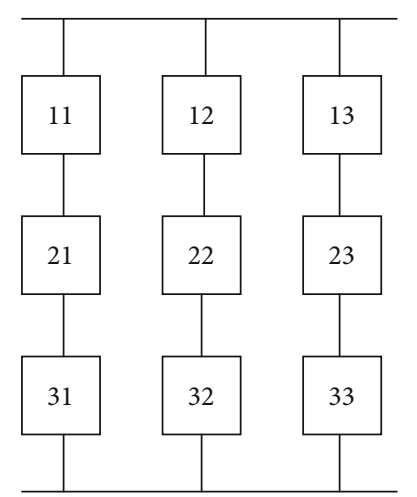

(a)

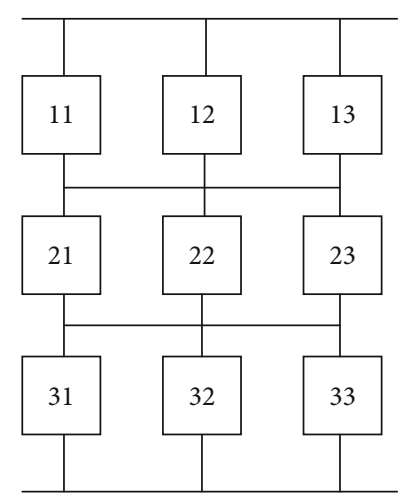

(b)

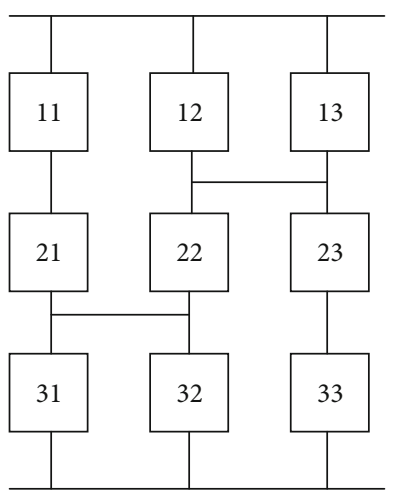

(c)

Figure 1: Various interconnection schemes: (a) SP array, (b) TCT array, and (c) BL array [7].

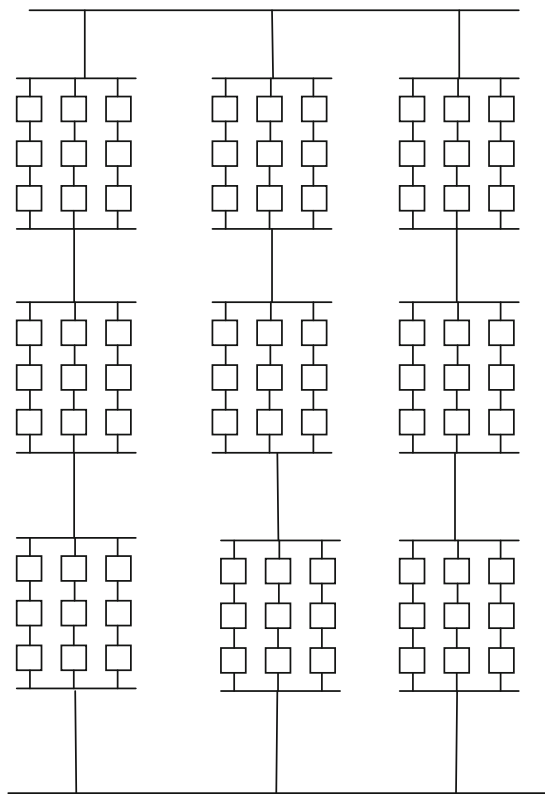

(a)

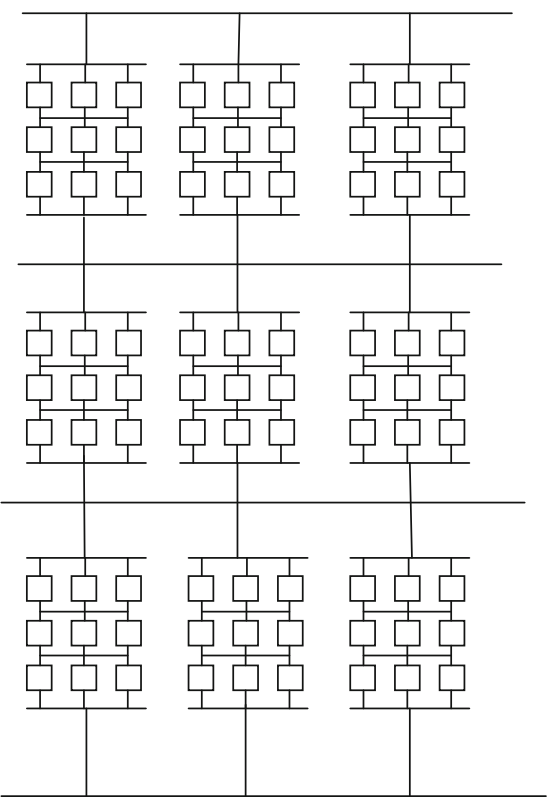

(b)

FIGURE 2: Large-scale PV arrays having subarrays with various interconnections: (a) SP array with SP subarrays and (b) TCT array with TCT subarrays [9]. 
comparison has been made between the subarrays with SP and TCT wiring (see Figure 2). The results demonstrate that there is more improvement in the global MPP by using subarrays with TCT wiring.

Even with the advantages of the TCT array compared with other arrays, the losses caused by partial shading are reduced in this scheme, provided that the shading effect is distributed almost uniformly throughout the PV array. To alleviate the shading effect, several studies have been carried out in the literature as dynamic and static reconfigurations.

PV array reconfiguration strategies are broadly classified into (i) static PV array reconfiguration (SPVAR) and (ii) dynamic PV array reconfiguration (DPVAR).

In DPVAR, the interconnection layout of PV modules in the PV array is altered dynamically according to irradiance levels to make the irradiance to all rows of the PV array equal by means of switches and sensors [10]. In the following, some examples of DPVAR in the literature are presented. The electrical array reconfiguration (EAR) technique has been developed, which is based upon the irradiance equivalence principle for all rows of the PV array [11]. For forming rows of the PV array by means of modules with the same illumination levels, instantaneous current and voltage signals are required. Consequently, as reconfiguration must be applied to all the modules within the PV array to achieve higher efficiency, a large number of probable connections are required. To rectify this problem, the PV array can be divided into two parts as the fixed and adaptive module parts. While the former contains statically connected modules, the latter can be attached to the fixed part with various arrangements. Adapted from the current variation index (CVI) technique, a scanning algorithm has been introduced in [12], which allows the connections between the adaptive and fixed parts dependent on the measured output currents of each row [12]. To effectively disperse shading effects over the PV array, an optimization technique has been presented in [13], where the electrical connections are changed without any variations in the physical position of PV modules. In addition, to detect the optimum configuration, the genetic algorithm (GA) generating different switching arrangements under various shading conditions is employed. In this algorithm, the PV arrays with the closest current levels in each row are recommended to be chosen as the best possible option. An analog technique has been implemented in [14], with the difference that the particle swarm optimization (PSO) is applied to detect optimum configuration. Compared to GA, only one switching cycle is needed for greatly distributing shading effects over the PV array. A new reconfiguration method has been introduced in [15], where a greedy algorithm is utilized for a switching matrix controller providing the best reconnection of the PV array with a reduced amount of calculational time. As an advantage, this technique calls for a relatively lower number of iterations for specifying optimal reconfiguration than other techniques. An image processing strategy has been presented in [16], where PV array rows are created by means of the panels with isolation levels adjacent to each other. To implement, the shading pattern on PV modules is captured by using a camera and then directed to the shadow detection algorithm called the Canny edge algorithm, which

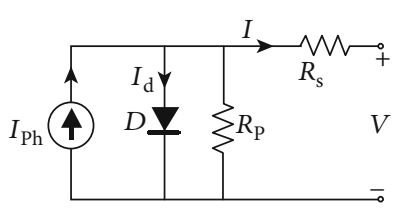

Figure 3: Simplified equivalent circuit of a PV cell [28].

is responsible for identifying the desired configuration by means of a switching matrix. Another dynamic reconfiguration method applicable for TCT connection has been introduced in [17], wherein to identify the shading locations, sky images happening in real time across the PV array are captured. Also, the desired interconnections of the PV array are chosen with the help of the switching matrix controller developed on the basis of IE.

In SPVAR, the physical location of the modules within the PV array is changed without varying the electrical connections so that the shading effect is distributed roughly uniformly throughout the PV array to enhance the output power. This strategy avoids using switches and sensors, resulting in decreased complexity in terms of implementation and control [18]. Several SPVAR strategies are reported in the literature. For arranging a $9 \times 9$ TCT array, a SuDoKu puzzle pattern targeting the distribution of shaded effects has been adopted [19], where the physical position of PV modules is altered without variations in any electrical connection. This pattern suffers from disadvantages, such as the need for additional wiring and ineffective shading distribution. Further, when implementing a large-scale PV array, the SuDoKu reconfiguration method is arduous and time-consuming. The SuDoKu puzzle pattern has been optimized to overcome these limitations, to reduce the effect of mutual shading, and to reduce wiring losses [20, 21]. The parameters like sun position, PV array geographical location, solar azimuth angle, and solar elevation (altitude angle) have an effect on dimensions of shadows, and they can be altered in $4 \times 2,2$ $\times 4,5 \times 5$, and $7 \times 5$ dimensions. To enhance power production under partial shading conditions, another puzzle pattern named Futoshiki has been developed in [22], which is a logicbased number puzzle, and its arrangement is carried out by means of a linear programming (LP) technique. In the developed pattern, " 1 " to " $n$ " are in such an order that there is no duplicate number in any row and column of a square matrix. For applying the SPVAR strategy to arrays with different dimensions, an algorithm has been presented in [18]. A new dominance square (DS) dependent on the mathematical puzzle is consolidated to identify the best composition for the $5 \times 5 \mathrm{PV}$ array [23]. To unravel the specified matrix, a logicbased number arrangement method positioning alphabets or numbers is applied. However, the method suffers from the painstaking work of physical repositioning. Another static technique is the competence square (CS), which is regarded as beneficial in terms of wise rearrangements of columns and rows as well as reductions in mismatch losses. Compared to the DS technique, its implementation on a PV array is also rather simpler [24]. SD-PAR is also another method that has been utilized in [25] to physically relocate the PV arrays with static configuration [25]. Reducing power losses and 


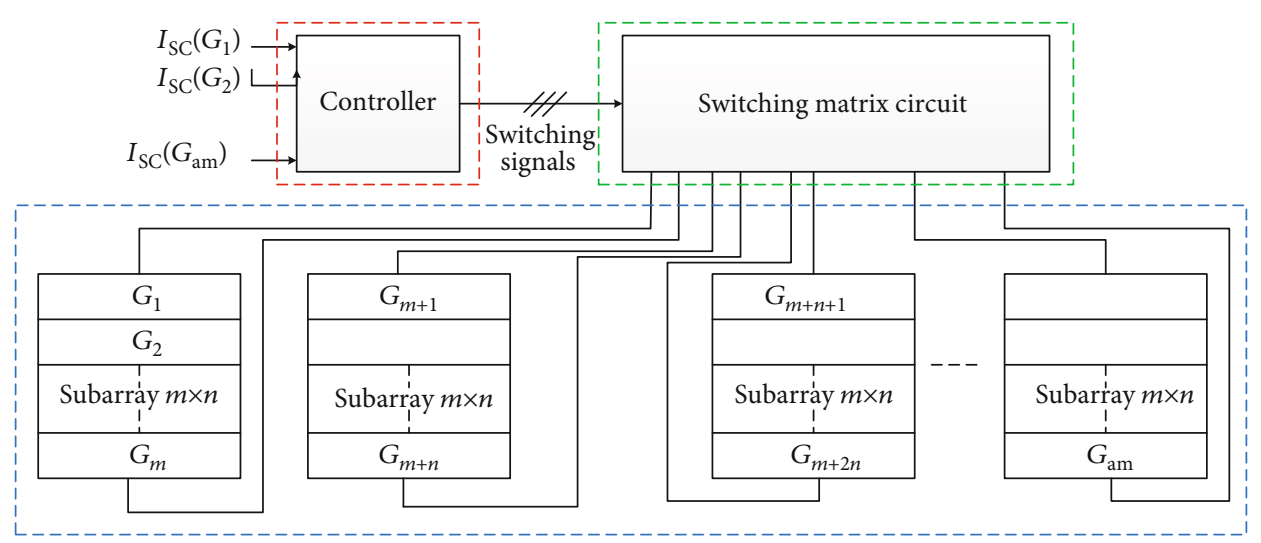

FIGURE 4: Connection architecture of the proposed two-step reconfiguration method.

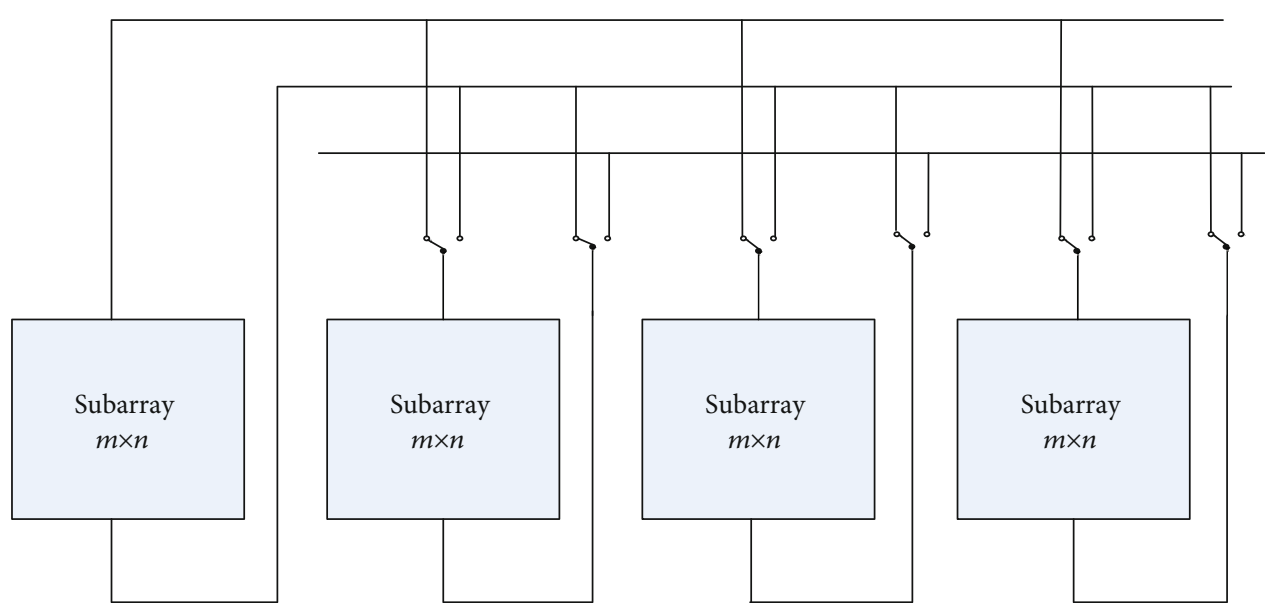

FIGURE 5: Internal circuit of the switching matrix for a $2 \times 2$ photovoltaic array.

increasing the output power of PV arrays under partial shading conditions are achieved using this method. A comparison between the SD-PAR method and other configurations such as SP, TCT, and BL is also presented in [25], and the results confirm that the SD-PAR method provides better performance and higher PV output power. Based on the skyscraper puzzle, another static reconfiguration technique has been introduced in [26] whose solution is reliant on sequencing a group of constructions having various heights. To address the burdensome interconnection ties and huge calculational time, a one-time reconfiguration of PV array is utilized. Furthermore, this technique enhances the performance and augments the generated power as a result of effectively distributing the shading on the PV array. The obtained results confirm that this technique outperforms TCT, $\mathrm{SuDoKu}$, and DS techniques in terms of the power generated. To disperse the shadows and increase the PV output power of four standard shading patterns, a physical displacement method based on the Lo Shu concept has been developed in [27]. A comparison between the Lo Shu method and other configurations such as CS, TCT, and DS approves that the Lo Shu method delivers upgraded performance and greater
PV output power. In SPVAR, increasing the array dimension results in installation and wiring complexity at locations with optimal irradiance. In DPVAR, increasing the array dimension leads to an increase in the number of switches and sensors required. These problems are dealt with in this paper by proposing a two-step method, which alleviates the problems related to both the static and dynamic reconfigurations for large-scale applications. In the first step, the modules within the large-scale PV array are divided into subarrays and wired in the form of static reconfiguration. In the second step, an algorithm is introduced to identify the most optimal connection in dynamic reconfiguration. The introduced algorithm searches for all possible connections and finally identifies the most optimal solution. As an advantage, this algorithm only utilizes short-circuit current values of subarray rows, which leads to the reduced numbers of required switches and sensors.

The rest of this paper is organized as follows. In Section 2, the modeling of a PV cell is presented. Section 3 presents the two-step proposed method. Furthermore, the proposed method is verified in Section 4 by simulations. Finally, future scope and conclusions are provided in Sections 5 and 6, respectively. 


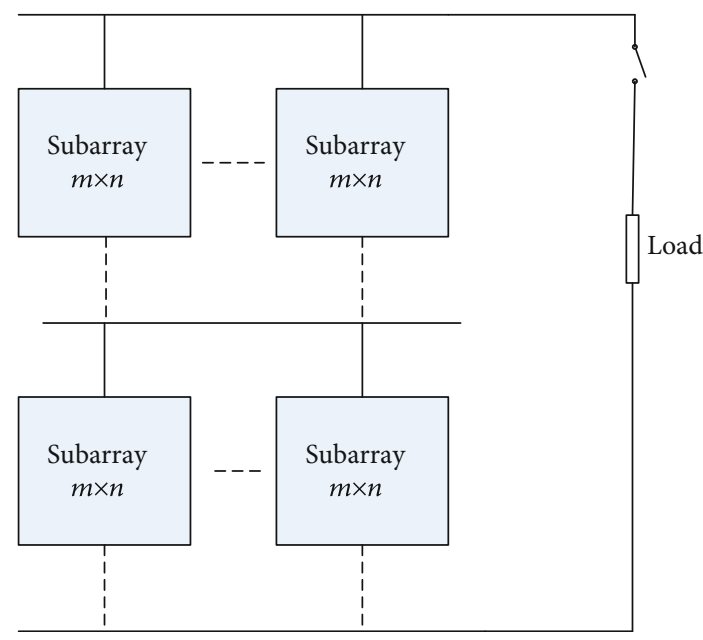

Figure 6: Connection of subarrays after dynamic reconfiguration.

\section{PV Cell Modeling}

The simplified equivalent circuit of a PV cell is depicted in Figure 3. The PV cell model consists of a diode connected in parallel to a current source. The current source generates the photoelectrical current $I_{\mathrm{Ph}}$ as (1), which is directly proportional to the light intensity. $R_{\mathrm{S}}$ represents the series resistance of the PN junction cell and has a great effect on the $I-V$ characteristic of the PV cell. The shunt resistance $R_{\mathrm{P}}$ is in an inversely proportional relation with leakage currents around the sides of the devices [28].

$$
I_{\mathrm{Ph}}=\frac{G}{G_{\mathrm{n}}} \cdot\left[I_{\mathrm{scn}}+k_{i} \cdot\left(T-T_{\mathrm{n}}\right)\right],
$$

where $G$ and $G_{\mathrm{n}}$ are the actual and nominal irradiations, respectively. $I_{\mathrm{scn}}$ is the nominal short-circuit current, $k_{i}$ is the temperature coefficient of the short-circuit current, and $T$ and $T_{\mathrm{n}}$ are the actual and nominal temperatures of the PV cell, respectively. The output $I-V$ characteristic of the PV cell can be expressed as

$$
I=I_{\mathrm{Ph}}-I_{\mathrm{sat}} \cdot\left(e^{V / V_{\mathrm{t}}}-1\right)-\frac{V+I \cdot R_{\mathrm{S}}}{R_{\mathrm{P}}},
$$

where $I$ and $V$ are the output current and voltage, respectively. $I_{\text {sat }}$ is the saturation current, and $V_{\mathrm{t}}$ is the thermal voltage.

\section{The Proposed PV Array Reconfiguration Method}

To lessen the shading effect, TCT array reconfiguration in the forms of dynamic and static reconfigurations can be utilized. In SPVAR, the physical place of the modules within the PV array alters without varying the electrical connections so that the shading effect is distributed roughly the same throughout the PV array to enhance the output power. This strategy avoids using switches and sensors, leading to the reduction of complexity relating to implementation and control [10].

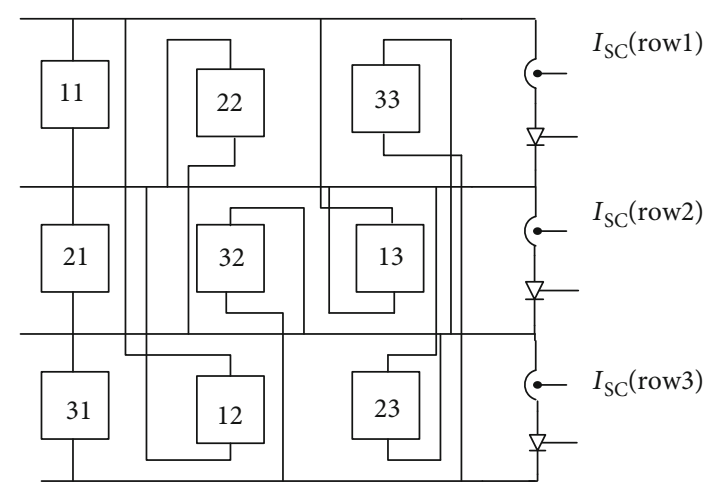

FIGURE 7: Block diagram for extracting short-circuit currents of rows in a $3 \times 3$ subarray.

In DPVAR, the interconnection arrangement of PV modules in the PV array is varied dynamically based upon irradiance levels to make the irradiance to all rows of the PV array equal using switches and sensors [7]. The complexity of wiring and installation in static reconfiguration and the large number of switches and sensors required in dynamic reconfiguration are major drawbacks of these two forms of reconfiguration in large-scale applications.

To overcome these drawbacks, a two-step reconfiguration method is proposed. In the first step, the modules within the PV array are divided into subarrays with wiring in static reconfiguration instead of being wired in the form of a largescale PV array. In the second step, an algorithm is introduced for dynamic reconfiguration. The introduced algorithm searches for all the possible connections for subarrays and finally identifies the most optimal solution. Dividing the PV array into subarrays results in relatively simpler installation and wiring in addition to locating them in the most optimal irradiation positions. Moreover, the introduced algorithm only utilizes short-circuit current values of subarray rows, leading to a reduced number of switches and sensors required. The connection architecture of the proposed twostep reconfiguration method is depicted in Figure 4. As seen, this architecture contains three main parts. The first part (in dashed blue line) consists of subarrays in $m \times n$ dimension, where the total irradiation of each row is denoted by $G$. The second part (in dashed red line) is the controller whose inputs are the short-circuit current of each row of the subarrays. The third part (in dashed green line) is the switching matrix circuit, which presents the connection of subarrays in the form of a TCT array.

The internal circuit of the switching matrix for a $2 \times 2 \mathrm{PV}$ array is demonstrated in Figure 5. The switches employed in this circuit are single-pole $m$-throws, and the required number of them can be calculated as

$$
N_{\mathrm{sw}}=2 N_{\mathrm{pv}}-2
$$

where $N_{\text {sw }}$ and $N_{\text {pv }}$ are the number of switches and subarrays, respectively.

3.1. Reconfiguration Process. To distribute the shading effect roughly uniformly throughout the PV array, the physical 


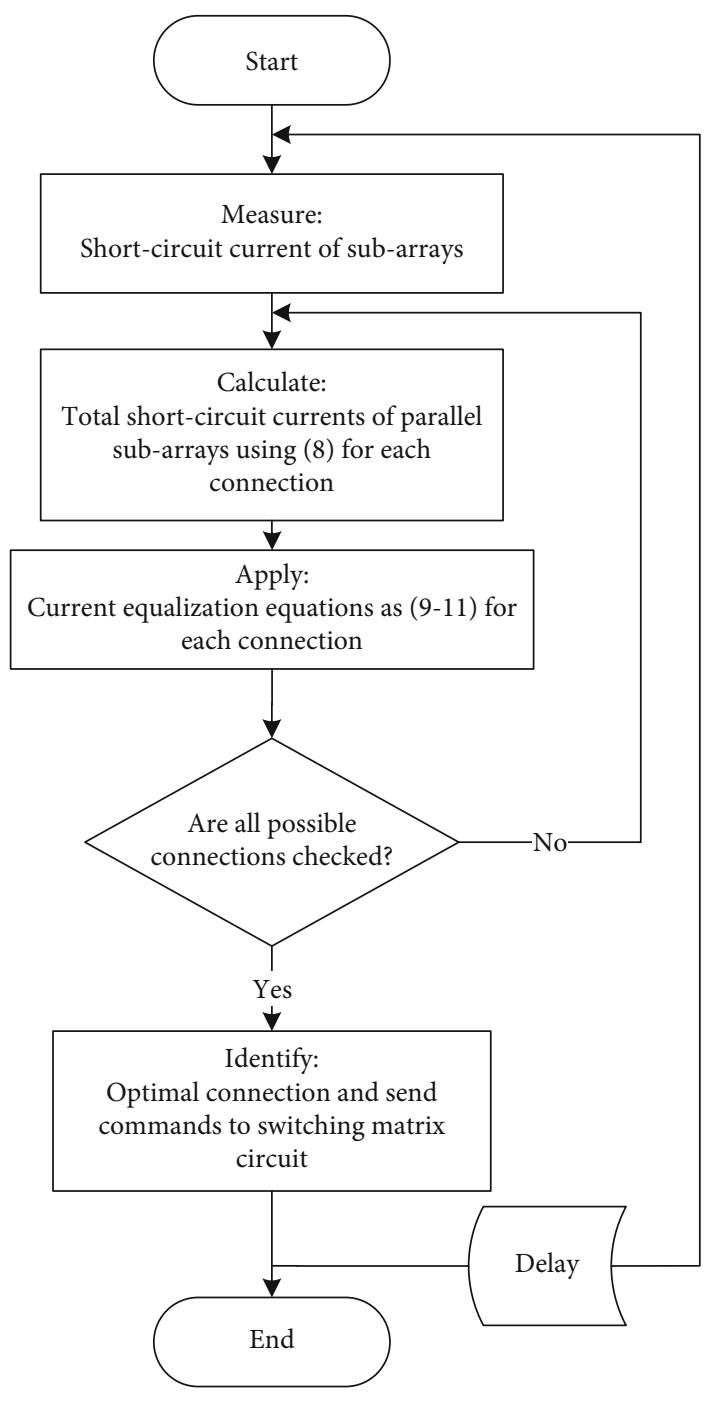

FIGURE 8: Flow chart of the introduced algorithm.

location of the modules within the PV array is altered. To do so, in the first step of the proposed method, the subarrays are wired as static reconfiguration. The physical location of the modules in the proposed method is determined as follows:

$$
\begin{aligned}
& Y_{i j}=X_{k j} \quad(i=1,2, \cdots, m \text { and } j=1,2, \cdots, n), \\
& k=(i+(j-1) d)=\left\{\begin{array}{l}
k, \quad k<m, \\
k-m, \quad \text { otherwise. }
\end{array}\right.
\end{aligned}
$$

For an $m \times n$ subarray, the distance of separation $d$ is an index that denotes the amount of module variation in each row and can be calculated as

$$
d=\operatorname{ceil}(\sqrt{m})
$$

where $i$ and $j$ are the number of the previous row and column of the module, respectively. Also, $k$ represents the number of new rows of the module. $m$ and $n$ are the size of subarray rows and columns, respectively.
TABLE 1: PV module parameter values.

\begin{tabular}{lc}
\hline Parameter & Value \\
\hline Module power & $83.23 \mathrm{~W}$ \\
Open circuit voltage & $12.64 \mathrm{~V}$ \\
Short-circuit current & $8.64 \mathrm{~A}$ \\
Nominal voltage & $10.32 \mathrm{~V}$ \\
Nominal current & $8.07 \mathrm{~A}$ \\
Number of series cells & 20 \\
\hline
\end{tabular}

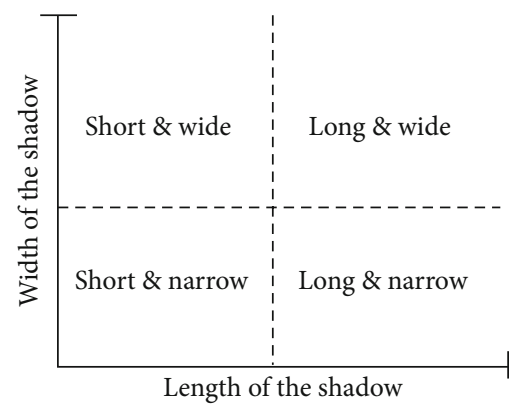

Figure 9: Various types of shading shape [29].

If the variations in the physical location of the modules yield an existing value of " $k$," then an offset value of " 1 " is added. The initial component of the first row is regarded as "1." The first-row indices of the left columns are determined by adding " $d$ " to the former index. If the sum is more than the size of the row, " $m$ " is subtracted from the sum. If this subtraction results in an index that exists already, the new index will be determined by adding an offset of " 1 " to the final amount. This procedure is repeated until all the indices in the first row are determined. If the number of rows is fewer than that of columns, the indices in the $(m+i)^{\text {th }}$ column will be the same as those in the $i^{\text {th }}$ column. The indices for the second row are determined by increasing the first-row indices.

In the second step and after applying static reconfiguration for wiring the subarrays, they are connected to each other in the form of a TCT array using dynamic reconfiguration. In this step, the subarrays are placed in the rows of the TCT array in such a way that a balance is held in the rows of the TCT array and the current distance and radiation distance of the rows are as close as possible. Figure 6 illustrates the subarray connection after dynamic reconfiguration. Balancing between TCT array rows is probable by measuring the short-circuit current of the subarray rows and then applying the proposed algorithm and command to the switching matrix, which creates an electrical connection locating the appropriate subarrays in the TCT array rows.

Illumination affects the short-circuit current of the module within the PV array, so only the short-circuit currents of the subarray rows are required, and there is no need to measure parameters like voltage and temperature.

The number of current sensors can be calculated as

$$
\mathrm{ssc}=m \times N_{\mathrm{pv}},
$$

where $N_{\mathrm{pv}}$ is the number of subarrays. 


\begin{tabular}{|c|c|c|c|c|c|c|c|c|c|}
\hline 11 & 12 & 13 & 14 & 15 & 16 & 17 & 18 & 19 & 110 \\
\hline 21 & 22 & 23 & 24 & 25 & 26 & 27 & 28 & 29 & 210 \\
\hline 31 & 32 & 33 & 34 & 35 & 36 & 37 & 38 & 39 & 310 \\
\hline 41 & 42 & 43 & 44 & 45 & 46 & 47 & 48 & 49 & 410 \\
\hline 51 & 52 & 53 & 54 & 55 & 56 & 57 & 58 & 59 & 510 \\
\hline 61 & 62 & 63 & 64 & 65 & 66 & 67 & 68 & 69 & 610 \\
\hline 71 & 72 & 73 & 74 & 75 & 76 & 77 & 78 & 79 & 710 \\
\hline 81 & 82 & 83 & 84 & 85 & 86 & 87 & 88 & 89 & 810 \\
\hline 91 & 92 & 93 & 94 & 95 & 96 & 97 & 98 & 99 & 910 \\
\hline 101 & 102 & 103 & 104 & 105 & 106 & 107 & 108 & 109 & 1010 \\
\hline
\end{tabular}

\begin{tabular}{|c|c|c|c|c|c|c|}
\hline \begin{tabular}{l|l|}
11 & 42 \\
\end{tabular} & \begin{tabular}{|l|l}
23 & 5 \\
\end{tabular} & \begin{tabular}{l|l|}
54 & 35 \\
\end{tabular} & 11 & 42 & & \begin{tabular}{l|l|l|l|l}
4 & 35 \\
\end{tabular} \\
\hline & \begin{tabular}{|l|l}
33 & 1 \\
\end{tabular} & \begin{tabular}{l|l|}
14 & 45 \\
\end{tabular} & & 52 & & \\
\hline \begin{tabular}{l|l|}
31 & 12 \\
\end{tabular} & \begin{tabular}{|l|l|}
43 & 2 \\
\end{tabular} & \begin{tabular}{l|l}
24 & 55
\end{tabular} & 31 & 12 & 13 & \begin{tabular}{l|l}
24 & 55
\end{tabular} \\
\hline \begin{tabular}{l|l|}
41 & 22 \\
\end{tabular} & \begin{tabular}{|l|l}
53 & 3 \\
\end{tabular} & \begin{tabular}{l|l}
34 & 15 \\
\end{tabular} & & 22 & b3 & \begin{tabular}{l|l}
34 & 15 \\
\end{tabular} \\
\hline \begin{tabular}{l|l|}
51 & 32 \\
\end{tabular} & \begin{tabular}{|l|l}
13 & 4 \\
\end{tabular} & \begin{tabular}{l|l}
44 & 2 \\
\end{tabular} & & & & \\
\hline & \begin{tabular}{|l|l}
23 & 5 \\
\end{tabular} & 54 & 11 & 42 & & \\
\hline \begin{tabular}{l|l|}
2152 \\
\end{tabular} & \begin{tabular}{|l|l|l|}
33 & 1 \\
\end{tabular} & & 21 & 52 & & \\
\hline \begin{tabular}{|l|l|}
31 & 12 \\
\end{tabular} & \begin{tabular}{|l|l|}
432 \\
\end{tabular} & & 31 & 12 & & \\
\hline \begin{tabular}{l|l|}
41 & 22 \\
\end{tabular} & \begin{tabular}{|l|l}
53 & 3 \\
\end{tabular} & \begin{tabular}{l|l}
34 & 15 \\
\end{tabular} & 41 & 22 & 53 & \begin{tabular}{|l|l|}
34 & 15 \\
\end{tabular} \\
\hline \begin{tabular}{|l|l|}
51 & 32 \\
\end{tabular} & \begin{tabular}{|l|l}
13 & 4 \\
\end{tabular} & 442 & 51 & & & \\
\hline
\end{tabular}
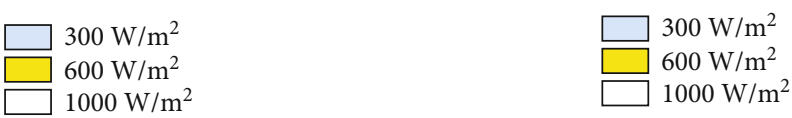

(a)

(b)

\begin{tabular}{|c|c|c|c|c|c|c|c|c|}
\hline & \begin{tabular}{l|l}
12 & 1
\end{tabular} & \begin{tabular}{|l|l|}
13 & 14 \\
\end{tabular} & 15 & 11 & 12 & & & \\
\hline & \begin{tabular}{l|l}
22 & 2
\end{tabular} & \begin{tabular}{|l|l|}
23 & 24 \\
\end{tabular} & 4 & 21 & 22 & & & \\
\hline & \begin{tabular}{|l|l}
32 & 3 \\
\end{tabular} & & 43 & & 32 & & & \\
\hline & \begin{tabular}{l|l|}
42 & 4
\end{tabular} & \begin{tabular}{|l|l|}
43 & 44 \\
\end{tabular} & & & 42 & & 4 & \\
\hline & $\begin{array}{ll}52 & 5\end{array}$ & \begin{tabular}{|l|l|l}
53 & 54
\end{tabular} & & & & & & \\
\hline & & & & & & & & \\
\hline & 22 & \begin{tabular}{l|l}
23 & 2 \\
\end{tabular} & 42 & & 22 & 23 & 24 & \\
\hline & & & & & 2 & & 34 & \\
\hline & & & & & & & & \\
\hline & & \begin{tabular}{l|l}
53 & 5
\end{tabular} & & & & & & \\
\hline
\end{tabular}

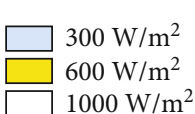

(c)

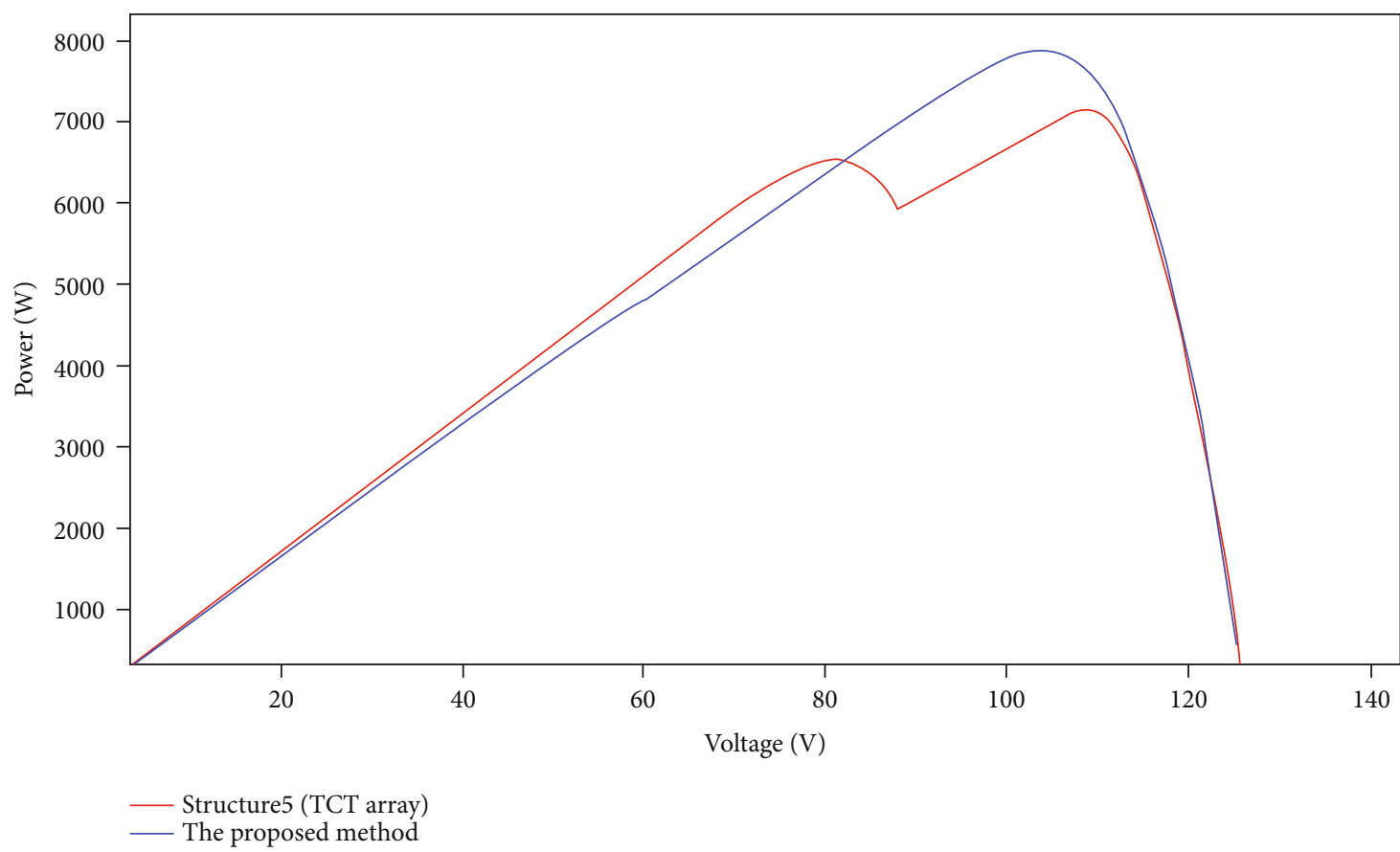

(d)

FIgURE 10: First shading pattern. (a) TCT array. (b) The proposed method before reconfiguration. (c) The proposed method after reconfiguration. (d) The PV array characteristics for the TCT array and the proposed method.

It is worth mentioning that as the load is powerless when measuring short-circuit currents and the measurement time is rather short, the power dissipation of the load can be ignored. In this step, the short-circuit currents of the subar- ray rows are measured using thyristors and switches at specified intervals and then are sent to the controller.

The block diagram for extracting the short-circuit currents of rows in a $3 \times 3$ subarray is depicted in Figure 7 . 


\begin{tabular}{|c|c|c|c|c|c|c|c|c|c|}
\hline 11 & 12 & 13 & 14 & 15 & 16 & 17 & 18 & 19 & 110 \\
\hline 21 & 22 & 23 & 24 & 25 & 26 & 27 & 28 & 29 & 210 \\
\hline 31 & 32 & 33 & 34 & 35 & 36 & 37 & 38 & 39 & 310 \\
\hline 41 & 42 & 43 & 44 & 45 & 46 & 47 & 48 & 49 & 410 \\
\hline 51 & 52 & 53 & 54 & 55 & 56 & 57 & 58 & 59 & 510 \\
\hline 61 & 62 & 63 & 64 & 65 & 66 & 67 & 68 & 69 & 610 \\
\hline 71 & 72 & 73 & 74 & 75 & 76 & 77 & 78 & 79 & 710 \\
\hline 81 & 82 & 83 & 84 & 85 & 86 & 87 & 88 & 89 & 810 \\
\hline 91 & 92 & 93 & 94 & 95 & 96 & 97 & 98 & 99 & 910 \\
\hline 101 & 102 & 103 & 104 & 105 & 106 & 107 & 108 & 109 & 1010 \\
\hline
\end{tabular}

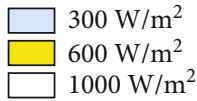

\begin{tabular}{|l|l|l|l|l|}
\hline 11 & 42 & 23 & 54 & 35 \\
\hline & 52 & 33 & 14 & 45 \\
\hline
\end{tabular} \begin{tabular}{lllll|l|}
\hline 21 & 52 & 33 & 14 & 45 \\
\hline 31 & 12 & 43 & 24 & 55 \\
\hline
\end{tabular} \begin{tabular}{llllll}
31 & 12 & 43 & 24 & 55 \\
\hline
\end{tabular} \begin{tabular}{llllll}
41 & 22 & 53 & 34 & 15 \\
\hline 51 & 32 & 13 & 44 & 25 \\
\hline
\end{tabular} \begin{tabular}{|l|l|l|l|l|}
\hline 51 & 32 & 13 & 44 & 25 \\
\hline
\end{tabular}

\begin{tabular}{|l|l|l|l|l|}
\hline 11 & 42 & 23 & 54 & 35 \\
\hline
\end{tabular} \begin{tabular}{|l|l|l|l|l|}
\hline 21 & 52 & 33 & 14 & 45 \\
\hline 31 & 12 & 43 & 24 & 5 \\
\hline
\end{tabular} \begin{tabular}{lllllll}
31 & 12 & 43 & 24 & 55 \\
\hline
\end{tabular} \begin{tabular}{|l|l|l|l|l|}
\hline 41 & 22 & 53 & 34 & 15 \\
\hline 51 & 32 & 13 & 4 & 25 \\
\hline
\end{tabular} \begin{tabular}{|l|l|l|l|l|}
\hline 51 & 32 & 13 & 44 & 25 \\
\hline
\end{tabular}

\begin{tabular}{|l|l|l|l|l|}
\hline 11 & 42 & 23 & 54 & 35 \\
\hline 21 & 52 & 33 & 14 & 45 \\
\hline 31 & 12 & 43 & 24 & 55 \\
\hline 41 & 22 & 53 & 34 & 15 \\
\hline 51 & 32 & 13 & 44 & 25 \\
\hline
\end{tabular}

\begin{tabular}{|l|l|l|l|l|}
\hline 11 & 42 & 23 & 54 & 35 \\
\hline
\end{tabular} \begin{tabular}{|l|l|l|l|l|}
\hline 21 & 52 & 33 & 14 & 45 \\
\hline
\end{tabular} \begin{tabular}{|llllll}
\hline 31 & 12 & 43 & 24 & 55 \\
\hline 4 & & &
\end{tabular} \begin{tabular}{|ll|l|l|l|}
\hline 41 & 22 & 53 & 34 & 15 \\
\hline 51 & 32 & 13 & 4 & 25 \\
\hline
\end{tabular}

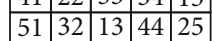

(a)

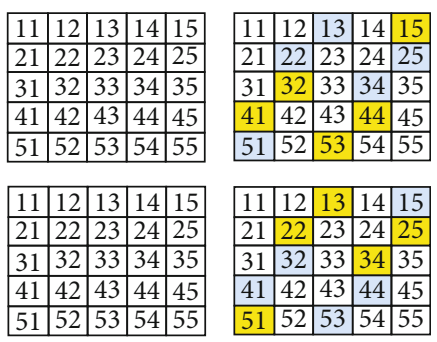

(b)

(c)

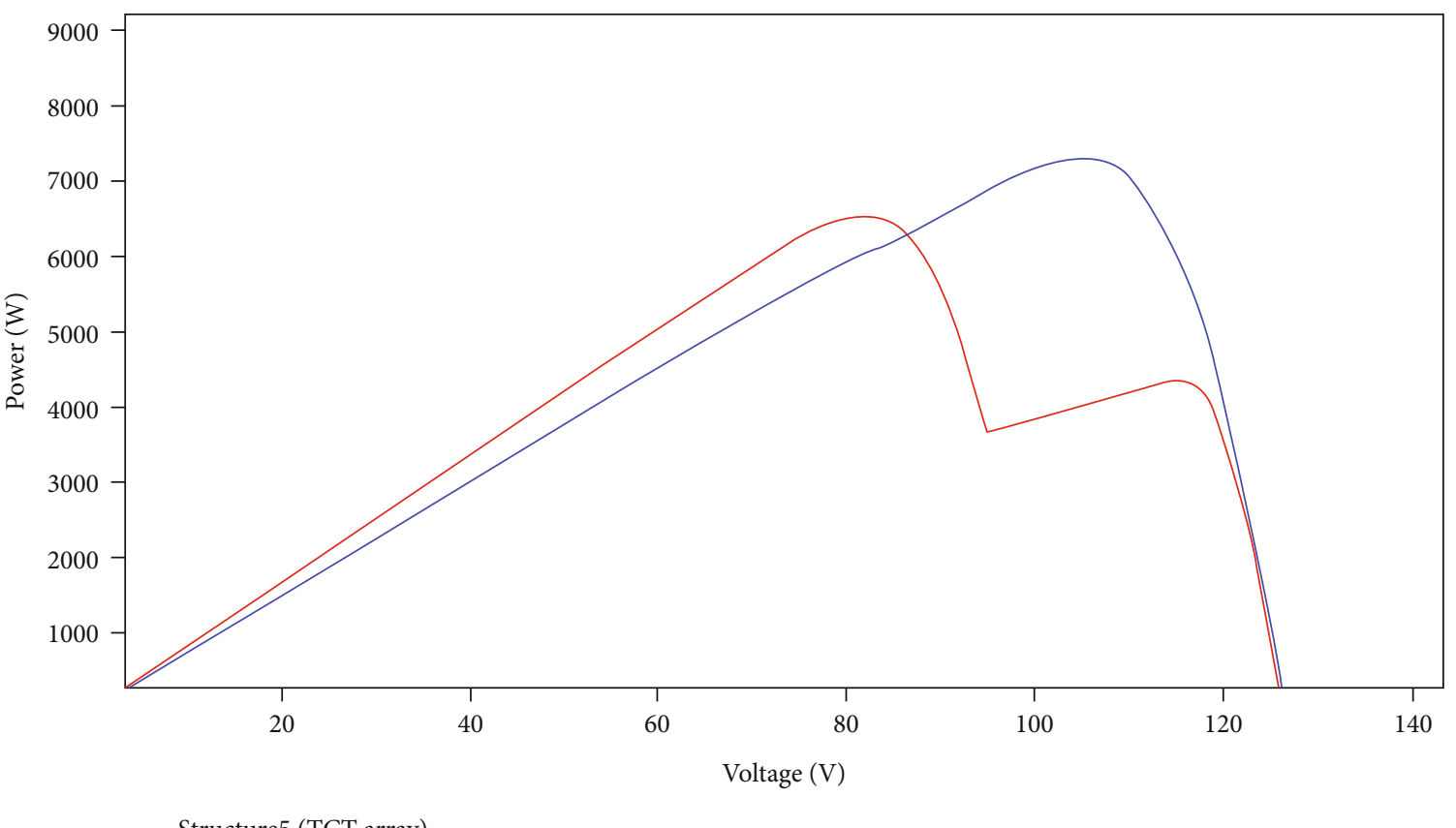

(d)

Figure 11: Second shading pattern. (a) TCT array. (b) The proposed method before reconfiguration. (c) The proposed method after reconfiguration. (d) The PV array characteristics for the TCT array and the proposed method.

The flowchart of the introduced algorithm is also presented in Figure 8. According to the extracted shortcircuit currents and equations (8)-(10), the controller employs the introduced algorithm to identify the optimal connections and send the appropriate commands to the switching matrix circuit.

$$
I_{1=} \sum_{1}^{N} I_{\mathrm{SC}(\min )}, \cdots, I_{m=} \sum_{1}^{N} I_{\mathrm{SC}(\max )},
$$




\begin{tabular}{|c|c|c|c|c|c|c|c|c|c|}
\hline 11 & 12 & 13 & 14 & 15 & 16 & 17 & 18 & 19 & 110 \\
\hline 21 & 22 & 23 & 24 & 25 & 26 & 27 & 28 & 29 & 210 \\
\hline 31 & 32 & 33 & 34 & 35 & 36 & 37 & 38 & 39 & 310 \\
\hline 41 & 42 & 43 & 44 & 45 & 46 & 47 & 48 & 49 & 410 \\
\hline 51 & 52 & 53 & 54 & 55 & 56 & 57 & 58 & 59 & 510 \\
\hline 61 & 62 & 63 & 64 & 65 & 66 & 67 & 68 & 69 & 610 \\
\hline 71 & 72 & 73 & 74 & 75 & 76 & 77 & 78 & 79 & 710 \\
\hline 81 & 82 & 83 & 84 & 85 & 86 & 87 & 88 & 89 & 810 \\
\hline 91 & 92 & 93 & 94 & 95 & 96 & 97 & 98 & 99 & 910 \\
\hline 101 & 102 & 103 & 104 & 105 & 106 & 107 & 108 & 109 & 1010 \\
\hline
\end{tabular}

$\square 00 \mathrm{~W} / \mathrm{m}^{2}$
$\square 00 \mathrm{~W} / \mathrm{m}^{2}$
$1000 \mathrm{~W} / \mathrm{m}^{2}$ \begin{tabular}{|l|l|l|l|l|l|l|l|l|l|}
\hline 11 & 42 & 23 & 54 & 35 \\
\hline
\end{tabular}

\begin{tabular}{lllllll|l|l|l|l|l|l|l|}
\hline 21 & 52 & 33 & 14 & 45 \\
\hline 21 & 52 & 33 & 14 & 45 \\
\hline
\end{tabular}

\begin{tabular}{lllllll|l|lllllll}
\hline 31 & 12 & 43 & 24 & 55 \\
\hline 31 & 12 & 43 & 24 & 55 \\
\hline
\end{tabular}

\begin{tabular}{|llllll|l|l|l|l|l|l|}
\hline 41 & 22 & 53 & 34 & 15 \\
\hline 41 & 22 & 53 & 34 & 15 \\
\hline
\end{tabular}

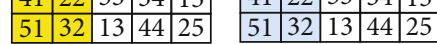

\begin{tabular}{|l|l|l|l|l|l|l|l|l|l|}
\hline 11 & 42 & 23 & 54 & 35 \\
\hline
\end{tabular}

\begin{tabular}{|lll|l|l|l|l|l|l|l|l|l|}
11 & 11 & 42 & 23 & 54 & 35 \\
\hline 21 & 52 & 33 & 14 & 45 & 33 & 14 & 45 \\
\hline
\end{tabular}

\begin{tabular}{|l|l|l|l|l|l|l|l|l|l|l|}
\hline 31 & 12 & 43 & 24 & 55 \\
\hline 31 & 12 & 43 & 24 & 55 \\
\hline
\end{tabular}

\begin{tabular}{|llllll|l|l|l|l|l|l|}
\hline 41 & 22 & 53 & 34 & 15 \\
\hline 41 & 22 & 53 & 34 & 15 \\
\hline
\end{tabular}

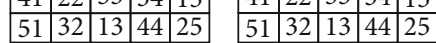

(a)

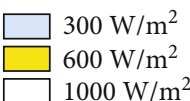

(b)

\begin{tabular}{|c|c|c|c|c|c|}
\hline \begin{tabular}{l|l}
1 & 12
\end{tabular} & 13 & \begin{tabular}{|l|l|}
14 & 15
\end{tabular} & \begin{tabular}{|l|l|}
1 & 12 \\
\end{tabular} & \begin{tabular}{l|l}
13 & 1 \\
\end{tabular} & \begin{tabular}{l|l|}
14 & 15
\end{tabular} \\
\hline \begin{tabular}{l|l|}
21 & 22 \\
\end{tabular} & 23 & \begin{tabular}{|l|l|}
24 & 25 \\
\end{tabular} & \begin{tabular}{|l|l|}
21 & 22 \\
\end{tabular} & & \begin{tabular}{l|l|}
24 & 25 \\
\end{tabular} \\
\hline & 33 & 343 & \begin{tabular}{|l|l|}
31 & 32 \\
\end{tabular} & 333 & \begin{tabular}{l|l|}
34 & 35 \\
\end{tabular} \\
\hline \begin{tabular}{l|l}
41 & 42 \\
\end{tabular} & 43 & 44 & \begin{tabular}{|l|l|}
41 & 42 \\
\end{tabular} & \begin{tabular}{|l|l}
43 \\
\end{tabular} & \begin{tabular}{l|l}
44 & 45 \\
\end{tabular} \\
\hline $\begin{array}{ll}152 \\
\end{array}$ & 53 & & \begin{tabular}{|l|l|}
51 & 52 \\
\end{tabular} & & \\
\hline 1 & & & & & \\
\hline 22 & 23 & & 21 & 23 & \\
\hline \begin{tabular}{l|l|}
31 & 32 \\
\end{tabular} & 33 & 34 & 32 & 33. & \\
\hline & 43 & & \begin{tabular}{|l|l|}
41 & 42 \\
\end{tabular} & 43 & \\
\hline \begin{tabular}{l|l}
51 & 52 \\
\end{tabular} & 53 & 54 & \begin{tabular}{|l|l|}
51 & 52 \\
\end{tabular} & 53 & 545 \\
\hline
\end{tabular}

$\square 00 \mathrm{~W} / \mathrm{m}^{2}$
$600 \mathrm{~W} / \mathrm{m}^{2}$
$1000 \mathrm{~W} / \mathrm{m}^{2}$

(c)

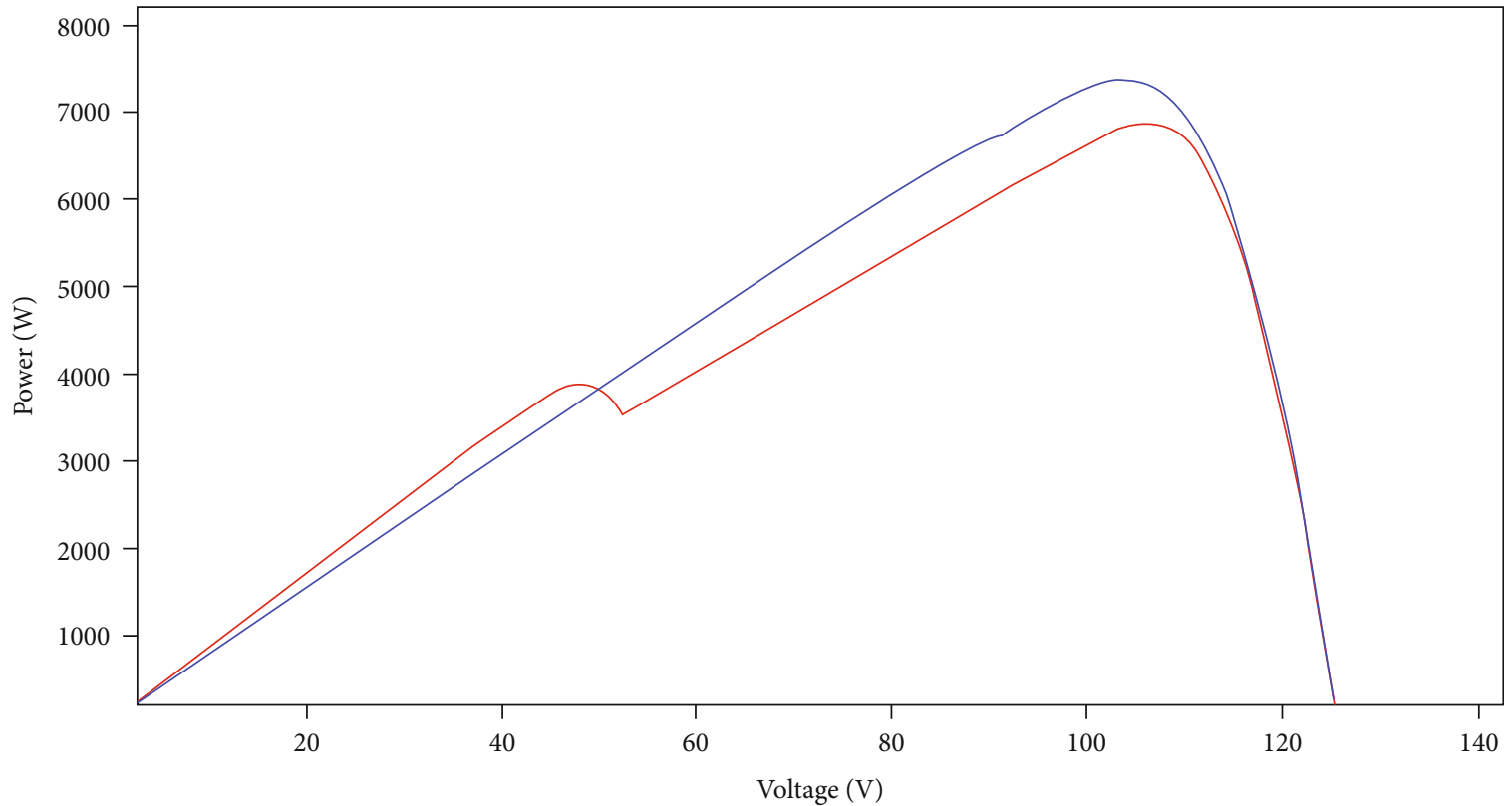

- Structure5 (TCT array)

- The proposed method

(d)

FIGURE 12: Third shading pattern. (a) TCT array. (b) The proposed method before reconfiguration. (c) The proposed method after reconfiguration. (d) The PV array characteristics for the TCT array and the proposed method.

$$
\begin{gathered}
I_{\max }=\max \left(I_{1}, \cdots, I_{m}, \cdots, I_{M}\right), \\
I_{\min }=\min \left(I_{1}, \cdots, I_{m}, \cdots, I_{M}\right), \\
\text { CEI }=\max I-\min I,
\end{gathered}
$$

where $N$ is the number of subarrays in each row of the TCT array and $m$ is the number of subarray rows. As each subarray includes $m$ rows, each subarray could have $m$ different currents depending on the radiation on the modules of each row. In other words, according to (8), in each row 


\begin{tabular}{|c|c|c|c|c|c|c|c|c|c|}
\hline 11 & 12 & 13 & 14 & 15 & 16 & 17 & 18 & 19 & 110 \\
\hline 21 & 22 & 23 & 24 & 25 & 26 & 27 & 28 & 29 & 210 \\
\hline 31 & 32 & 33 & 34 & 35 & 36 & 37 & 38 & 39 & 310 \\
\hline 41 & 42 & 43 & 44 & 45 & 46 & 47 & 48 & 49 & 410 \\
\hline 51 & 52 & 53 & 54 & 55 & 56 & 57 & 58 & 59 & 510 \\
\hline 61 & 62 & 63 & 64 & 65 & 66 & 67 & 68 & 69 & 610 \\
\hline 71 & 72 & 73 & 74 & 75 & 76 & 77 & 78 & 79 & 710 \\
\hline 81 & 82 & 83 & 84 & 85 & 86 & 87 & 88 & 89 & 810 \\
\hline 91 & 92 & 93 & 94 & 95 & 96 & 97 & 98 & 99 & 910 \\
\hline 101 & 102 & 103 & 104 & 105 & 106 & 107 & 108 & 109 & 1010 \\
\hline
\end{tabular}

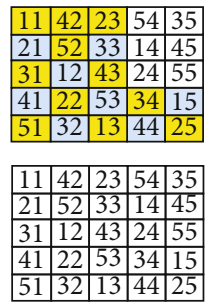

\begin{tabular}{|l|l|l|l|l|l|}
\hline 11 & 42 & 23 & 54 & 35 \\
\hline & & 5 & 33 & & 4 \\
\hline
\end{tabular}

\begin{tabular}{|l|lllll}
\hline 21 & 52 & 33 & 14 & 45 \\
\hline
\end{tabular}

\begin{tabular}{l|lll|l|l|}
\hline 31 & 12 & 43 & 24 & 55 \\
\hline
\end{tabular}

\begin{tabular}{lllllll}
\hline 41 & 22 & 53 & 34 & 15 \\
\hline
\end{tabular}

\begin{tabular}{l|l|l|l|l|}
\hline 51 & 32 & 13 & 44 & 25 \\
\hline
\end{tabular}

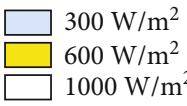

$\square 300 \mathrm{~W} / \mathrm{m}^{2}$

\begin{tabular}{|l|l|l|l|l|}
\hline 11 & 42 & 23 & 54 & 35 \\
\hline & & & 3
\end{tabular}

\begin{tabular}{|l|l|l|l|l|l|}
\hline 21 & 52 & 33 & 14 & 45 \\
\hline
\end{tabular}

\begin{tabular}{|l|l|l|l|l|}
31 & 12 & 43 & 24 & 55 \\
\hline
\end{tabular}

\begin{tabular}{lllllll}
41 & 22 & 53 & 34 & 15 \\
\hline & & 3 & 15 & 4 & 25 \\
\hline
\end{tabular}

\begin{tabular}{|l|l|l|l|l|l|}
\hline 51 & 22 & 53 & 34 & 15 \\
\hline
\end{tabular}

(b)

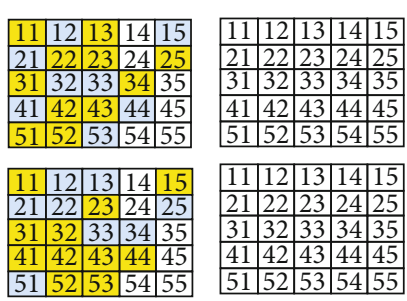

$300 \mathrm{~W} / \mathrm{m}^{2}$

$600 \mathrm{~W} / \mathrm{m}^{2}$

$1000 \mathrm{~W} / \mathrm{m}^{2}$

(c)

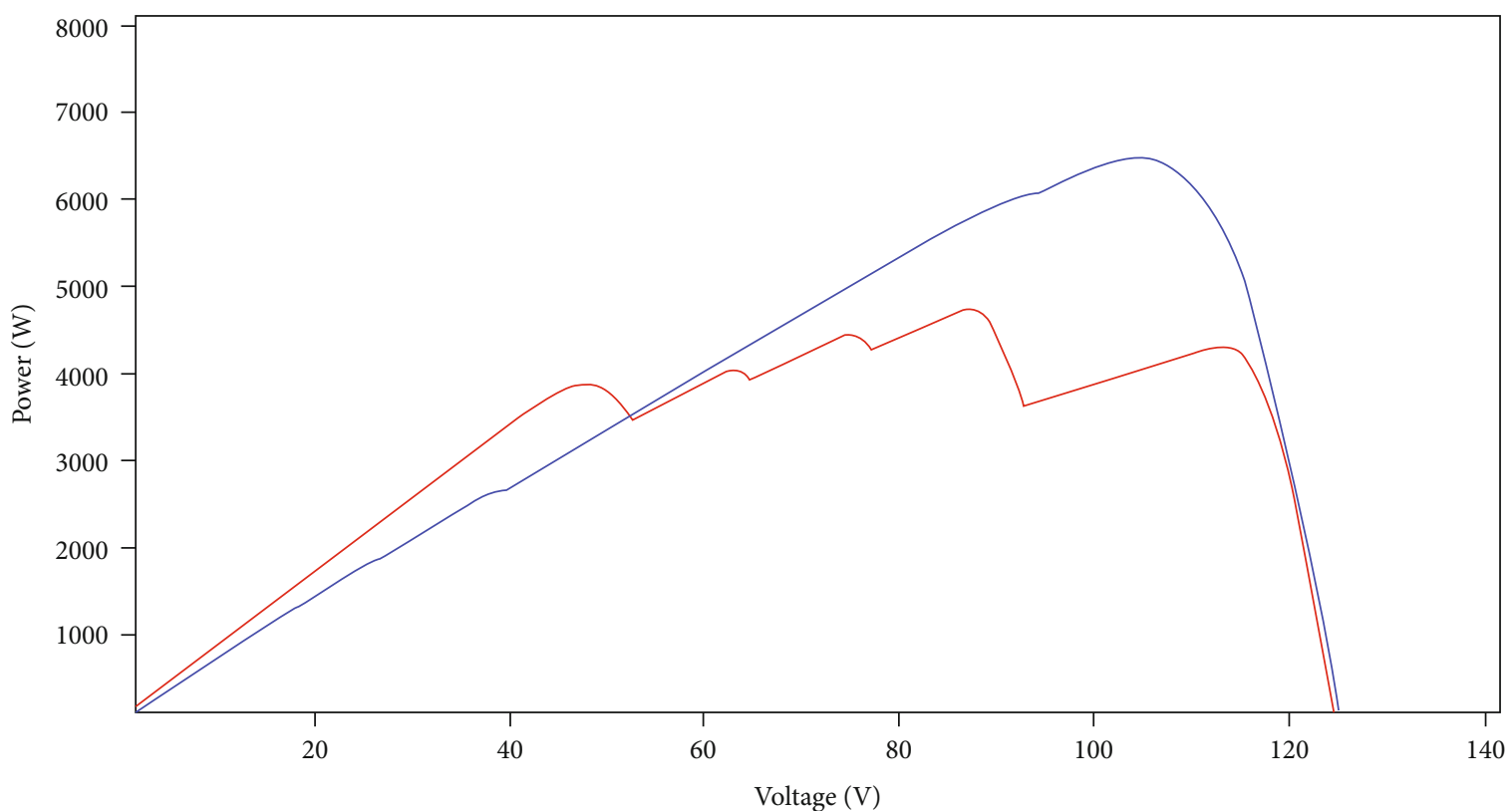

(d)

FIgURE 13: Fourth shading pattern. (a) TCT array. (b) The proposed method before reconfiguration. (c) The proposed method after reconfiguration. (d) The PV array characteristics for the TCT array and the proposed method.

of the TCT array, the short-circuit currents of the rows of the subarrays are added up from the lowest to the highest possible value. Therefore, $m$ different currents are created in each row of the TCT array. $M$ represents the total number of rows of subarrays in all the rows of the TCT array, and $I_{\max }$ and $I_{\min }$ are the maximum and minimum values of the currents of subarray rows, respectively. CEI is an index that selects the smallest difference between the total currents of subarray rows as the optimal connection, resulting in the global maximum power. 


\begin{tabular}{|c|c|c|c|c|c|c|c|c|c|}
\hline 11 & 12 & 13 & 14 & 15 & 16 & 17 & 18 & 19 & 110 \\
\hline 21 & 22 & 23 & 24 & 25 & 26 & 27 & 28 & 29 & 210 \\
\hline 31 & 32 & 33 & 34 & 35 & 36 & 37 & 38 & 39 & 310 \\
\hline 41 & 42 & 43 & 44 & 45 & 46 & 47 & 48 & 49 & 410 \\
\hline 51 & 52 & 53 & 54 & 55 & 56 & 57 & 58 & 59 & 510 \\
\hline 61 & 62 & 63 & 64 & 65 & 66 & 67 & 68 & 69 & 610 \\
\hline 71 & 72 & 73 & 74 & 75 & 76 & 77 & 78 & 79 & 710 \\
\hline 81 & 82 & 83 & 84 & 85 & 86 & 87 & 88 & 89 & 810 \\
\hline 91 & 92 & 93 & 94 & 95 & 96 & 97 & 98 & 99 & 910 \\
\hline 101 & 102 & 103 & 104 & 105 & 106 & 107 & 108 & 109 & 1010 \\
\hline
\end{tabular}

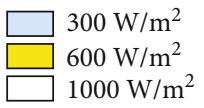

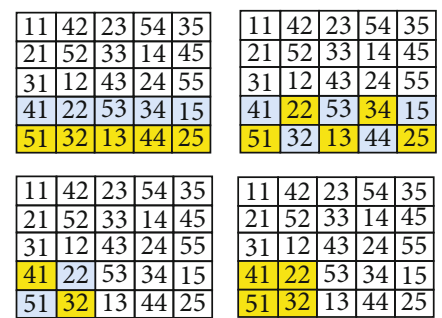

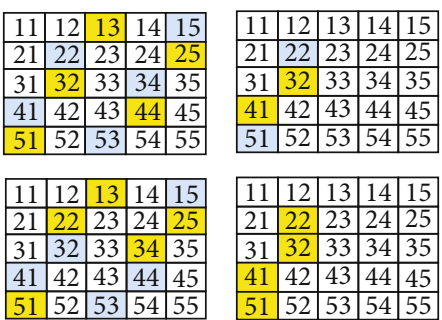

(b)

(c)

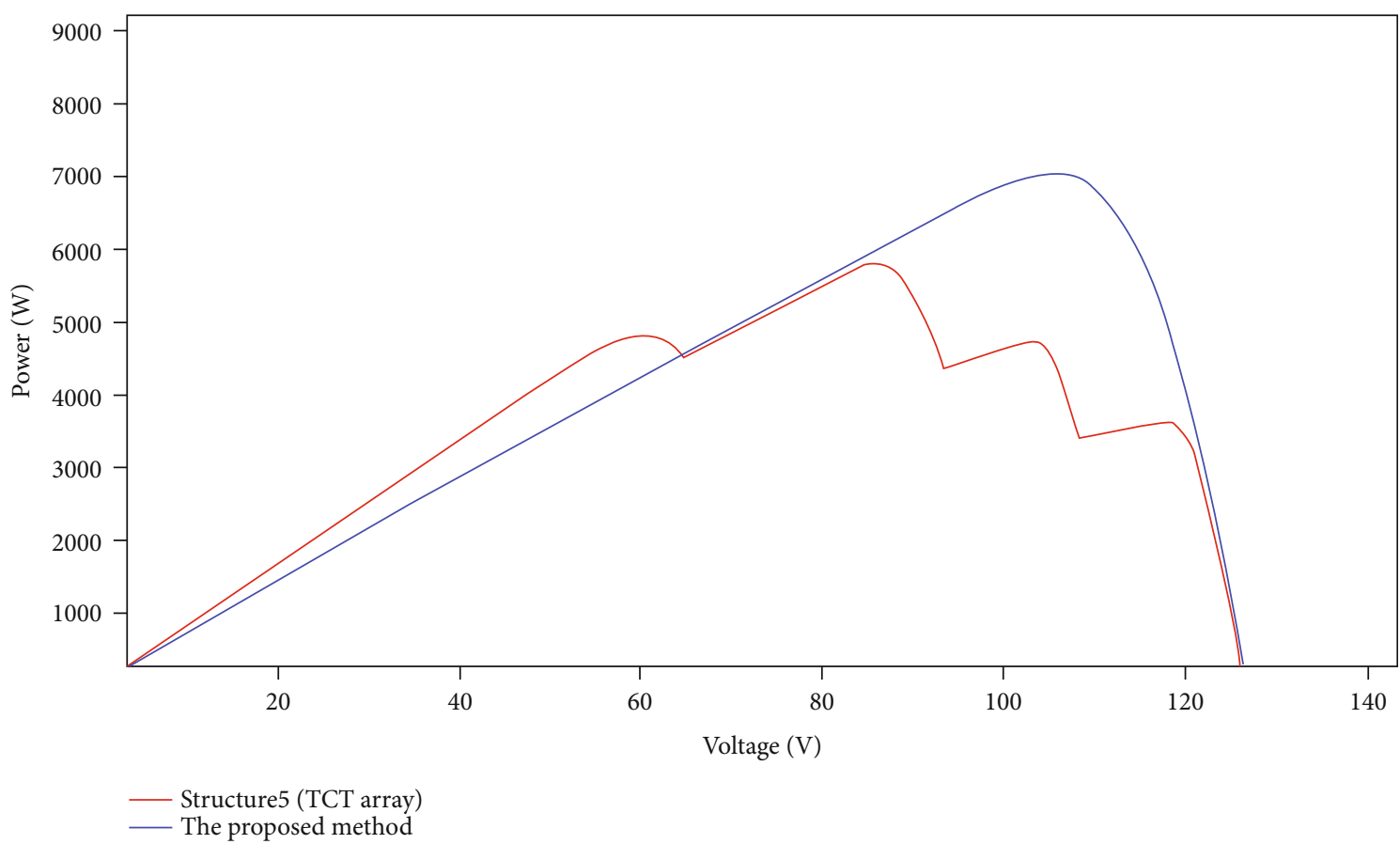

(d)

Figure 14: Fifth shading pattern. (a) TCT array. (b) The proposed method before reconfiguration. (c) The proposed method after reconfiguration. (d) The PV array characteristics for the TCT array and the proposed method.

\section{Simulation Study}

To verify the performance of the proposed method, six different simulations are performed in the MATLAB/Simulink platform, where a hundred modules under eight different shading patterns are wired, with the PV module parameter values provided in Table 1 . In the first structure, a hundred modules are divided into four $5 \times 5$ TCT subarrays, and connections of subarrays are in the form of a TCT array. In the second structure, a hundred modules are divided into four 


\begin{tabular}{|l|l|l|l|l|l|l|l|l|l|}
\hline 11 & 12 & 13 & 14 & 15 & 16 & 17 & 18 & 19 & 110 \\
\hline 21 & 22 & 23 & 24 & 25 & 26 & 27 & 28 & 29 & 210 \\
\hline 31 & 32 & 33 & 34 & 35 & 36 & 37 & 38 & 39 & 310 \\
\hline 41 & 42 & 43 & 44 & 45 & 46 & 47 & 48 & 49 & 410 \\
\hline 51 & 52 & 53 & 54 & 55 & 56 & 57 & 58 & 59 & 510 \\
\hline 61 & 62 & 63 & 64 & 65 & 66 & 67 & 68 & 69 & 610 \\
\hline 71 & 72 & 73 & 74 & 75 & 76 & 77 & 78 & 79 & 710 \\
\hline 81 & 82 & 83 & 84 & 85 & 86 & 87 & 88 & 89 & 810 \\
\hline 91 & 92 & 93 & 94 & 95 & 96 & 97 & 98 & 99 & 910 \\
\hline 101 & 102 & 103 & 104 & 105 & 106 & 107 & 108 & 109 & 1010 \\
\hline
\end{tabular}

\begin{tabular}{|l|l|l|l|l|l|l|l|l|l|}
\hline 11 & 42 & 23 & 54 & 35 \\
\hline & 11 & 42 & 23 & 54 & 35 \\
\hline & 52 & 33 & 14 & 45 & 21 & 52 & 33 & 14 & 55 \\
\hline
\end{tabular}

\begin{tabular}{lllllll|l|l|l|l|l|}
21 & 52 & 33 & 14 & 45 & 21 & 52 & 33 & 14 & 45 \\
\hline
\end{tabular}

\begin{tabular}{|l|l|l|l|l|l|l|l|l|l|}
\hline 31 & 12 & 43 & 24 & 55 & 31 & 12 & 43 & 24 & 55 \\
\hline 41 & 22 & 53 & 34 & 15 & &
\end{tabular}

\begin{tabular}{|l|l|l|l|l|l|l|l|l|l|}
41 & 22 & 53 & 34 & 15 \\
\hline 51 & 32 & 13 & 44 & 25 & 22 & 53 & 34 & 15 \\
\hline
\end{tabular}

\begin{tabular}{|l|lll|l|l|l|l|l|l|l|}
\hline 51 & 32 & 13 & 44 & 25 \\
\hline 51 & 32 & 13 & 44 & 25 \\
\hline
\end{tabular}

\begin{tabular}{|l|l|l|l|l|l|l|l|l|l|}
\hline 11 & 42 & 23 & 54 & 35 \\
\hline 11 & 42 & 23 & 54 & 35 \\
\hline 21 & 52 & 33 & 14 & 45 & 52 & 33 & 14 & 45 \\
\hline
\end{tabular}

\begin{tabular}{lllllll|l|l|l|l|l|}
21 & 52 & 33 & 14 & 45 & 21 & 52 & 33 & 14 & 45 \\
\hline
\end{tabular}

\begin{tabular}{|llllll|l|l|l|l|l|}
\hline 31 & 12 & 43 & 24 & 55 & 31 & 12 & 43 & 24 & 55 \\
\hline
\end{tabular}

\begin{tabular}{|l|l|l|l|l|l|l|l|l|l|}
\hline 41 & 22 & 53 & 34 & 15 & 41 & 22 & 53 & 34 & 15 \\
\hline
\end{tabular}

\begin{tabular}{|l|l|l|l|l|l|}
\hline 51 & 32 & 13 & 44 & 25 \\
\hline 51 & 32 & 13 & 44 & 25 \\
\hline
\end{tabular}

$\square 00 \mathrm{~W} / \mathrm{m}^{2}$
$\square$
$\square$
$1000 \mathrm{~W} / \mathrm{m}^{2}$

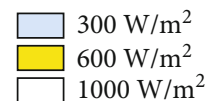

(a)

(b)

\begin{tabular}{|c|c|c|c|c|c|c|c|c|c|}
\hline & 12 & & & & 11 & 12 & 13 & 14 & \\
\hline & & & & & & 22 & 23 & & \\
\hline & & & 34 & & 1 & 22 & 33 & 4 & 3 \\
\hline & & & 44 & 45 & 41 & 42 & 43 & 44 & 4 \\
\hline & & b. & 54 & 55 & 51 & 52 & 53 & 54 & \\
\hline & & & & & & 12 & 13 & & \\
\hline & 2 & & 24 & 2 & 21 & 22 & 23 & 24 & \\
\hline & & & 34 & 35 & 31 & 32 & 33 & 34 & 3 \\
\hline & & & 44 & & 41 & 42 & 43 & 44 & 4 \\
\hline & 5 & & 54 & & 51 & 52 & 53 & 54 & \\
\hline
\end{tabular}

$300 \mathrm{~W} / \mathrm{m}^{2}$

$600 \mathrm{~W} / \mathrm{m}^{2}$

$1000 \mathrm{~W} / \mathrm{m}^{2}$

(c)

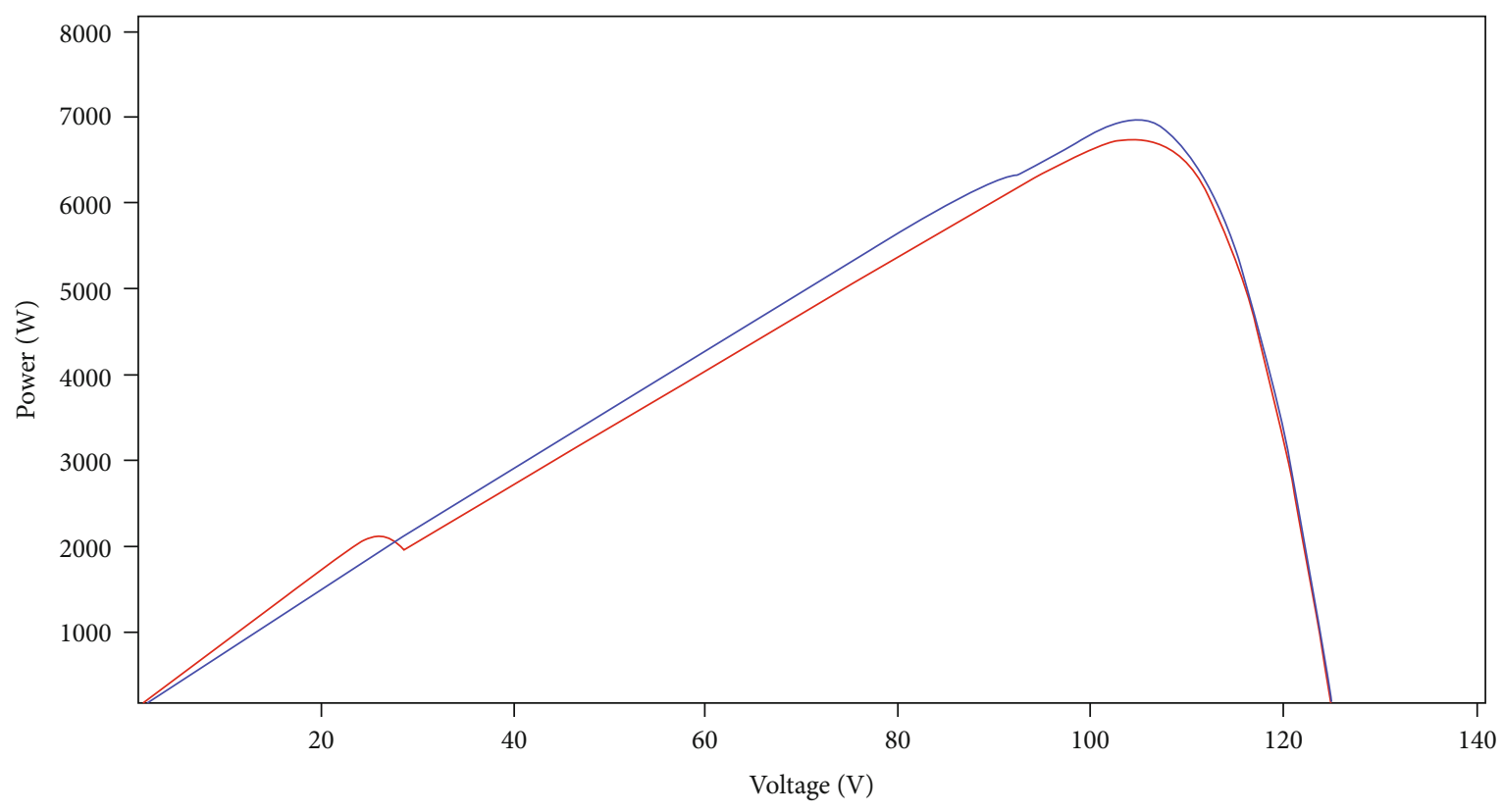

— Structure5 (TCT array)

The proposed method

(d)

FIgURE 15: Sixth shading pattern. (a) TCT array. (b) The proposed method before reconfiguration. (c) The proposed method after reconfiguration. (d) The PV array characteristics for the TCT array and the proposed method. 


\begin{tabular}{|c|c|c|c|c|c|c|c|c|c|}
\hline 11 & 12 & 13 & 14 & 15 & 16 & 17 & 18 & 19 & 110 \\
\hline 21 & 22 & 23 & 24 & 25 & 26 & 27 & 28 & 29 & 210 \\
\hline 31 & 32 & 33 & 34 & 35 & 36 & 37 & 38 & 39 & 310 \\
\hline 41 & 42 & 43 & 44 & 45 & 46 & 47 & 48 & 49 & 410 \\
\hline 51 & 52 & 53 & 54 & 55 & 56 & 57 & 58 & 59 & 510 \\
\hline 61 & 62 & 63 & 64 & 65 & 66 & 67 & 68 & 69 & 610 \\
\hline 71 & 72 & 73 & 74 & 75 & 76 & 77 & 78 & 79 & 710 \\
\hline 81 & 82 & 83 & 84 & 85 & 86 & 87 & 88 & 89 & 810 \\
\hline 91 & 92 & 93 & 94 & 95 & 96 & 97 & 98 & 99 & 910 \\
\hline 101 & 102 & 103 & 104 & 105 & 106 & 107 & 108 & 109 & 1010 \\
\hline
\end{tabular}

\begin{tabular}{|c|c|c|c|c|}
\hline 11 & 42 & 23 & 54 & 35 \\
\hline 21 & 52 & 33 & \begin{tabular}{|l|l}
14 \\
\end{tabular} & 45 \\
\hline 31 & 12 & 43 & 24 & 55 \\
\hline 41 & 22 & 53 & 34 & 15 \\
\hline 51 & 32 & 13 & 44 & 25 \\
\hline 11 & 42 & 23 & 54 & 35 \\
\hline 21 & 52 & 33 & \begin{tabular}{|l|l}
14 \\
\end{tabular} & 45 \\
\hline 31 & 12 & 43 & 24 & 55 \\
\hline 41 & 22 & 53 & 34 & 15 \\
\hline 51 & 32 & 13 & 44 & 25 \\
\hline
\end{tabular}

\begin{tabular}{|l|l|l|l|l|}
\hline 11 & 42 & 23 & 54 & 35 \\
\hline 21 & 52 & 33 & 14 & 45 \\
\hline
\end{tabular}

\begin{tabular}{|lll|l|l|l|}
\hline 21 & 52 & 33 & 14 & 45 \\
\hline 31 & 12 & 43 & 24 & 55 \\
\hline
\end{tabular}

\begin{tabular}{|l|l|l|l|l|}
\hline 31 & 12 & 43 & 24 & 55 \\
\hline 41 & 22 & 53 & 34 & 15 \\
\hline
\end{tabular}

\begin{tabular}{|lll|l|l|l|}
\hline 41 & 22 & 53 & 34 & 15 \\
\hline
\end{tabular}

\begin{tabular}{|l|l|l|l|l|}
\hline 51 & 32 & 13 & 44 & 25 \\
\hline
\end{tabular}

$\square 300 \mathrm{~W} / \mathrm{m}^{2}$
$\square 600 \mathrm{~W} / \mathrm{m}^{2}$
$\square 1000 \mathrm{~W} / \mathrm{m}^{2}$

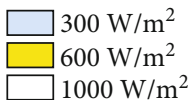

(a)

(b)

\begin{tabular}{|c|c|c|c|c|c|c|c|c|c|}
\hline 11 & 12 & 13 & 14 & 15 & 11 & 12 & 13 & 14 & 15 \\
\hline 21 & 22 & 23 & 24 & 25 & 21 & 22 & 23 & 24 & 25 \\
\hline 31 & 32 & 33 & 34 & 35 & 31 & 32 & 33 & 34 & 35 \\
\hline 41 & 42 & 43 & 44 & 45 & 41 & 42 & 43 & 44 & 45 \\
\hline 51 & 52 & 53 & 54 & 55 & 51 & 52 & 53 & 54 & 55 \\
\hline 11 & 12 & 13 & 14 & 15 & 11 & 12 & 13 & 14 & \\
\hline 21 & 22 & 23 & 24 & 25 & 21 & 22 & 23 & 24 & 25 \\
\hline 31 & 32 & 33 & 34 & 35 & 31 & 32 & 33 & 34 & 35 \\
\hline 41 & 42 & 43 & 44 & 45 & 41 & 42 & 43 & 44 & 45 \\
\hline 51 & 52 & 53 & 54 & 55 & 51 & 52 & 53 & 54 & \\
\hline
\end{tabular}

$\square 300 \mathrm{~W} / \mathrm{m}^{2}$

$600 \mathrm{~W} / \mathrm{m}^{2}$

$1000 \mathrm{~W} / \mathrm{m}^{2}$

(c)

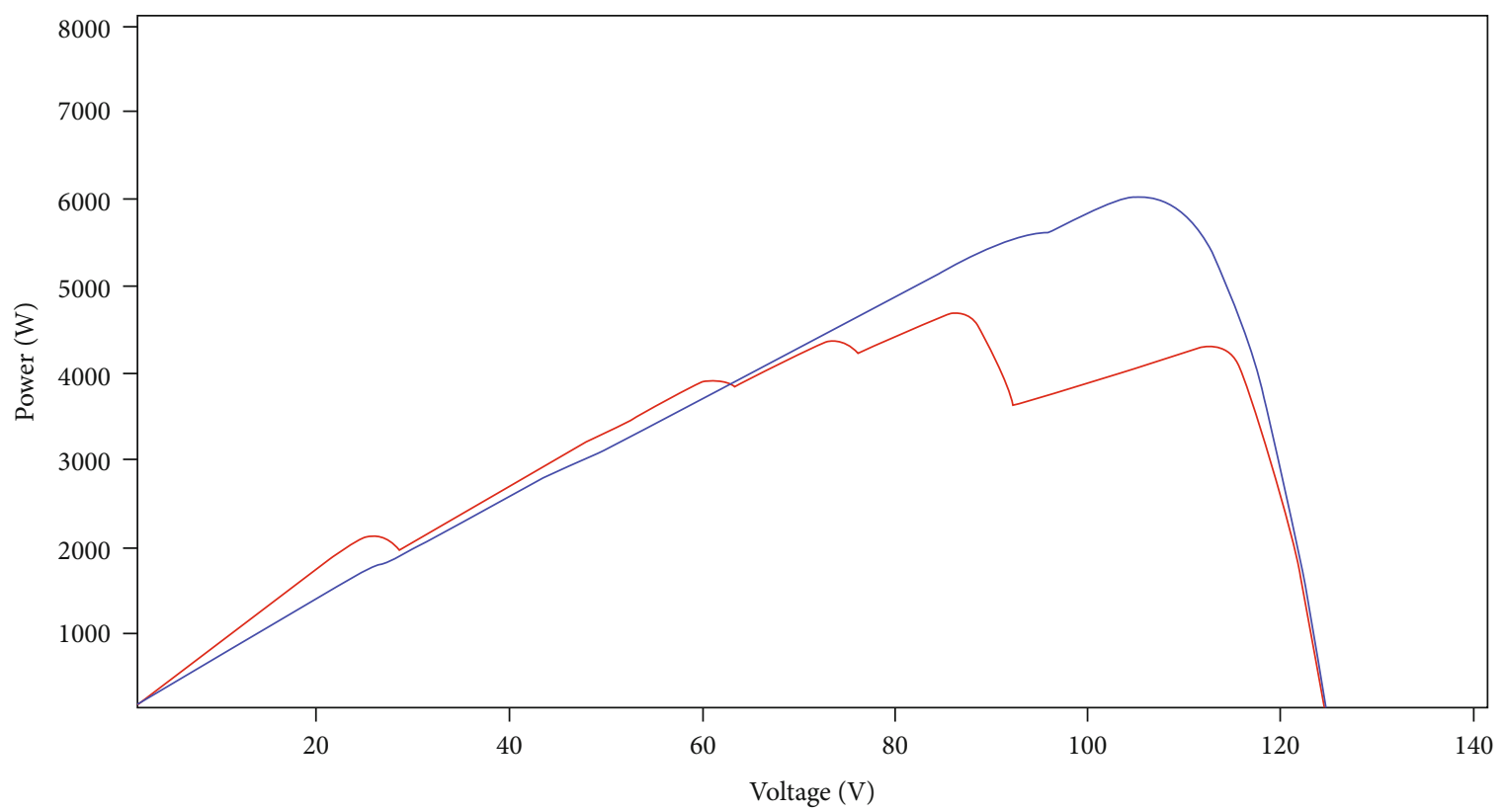

- Structure5 (TCT array)

- The proposed method

(d)

FIGURE 16: Seventh shading pattern. (a) TCT array. (b) The proposed method before reconfiguration. (c) The proposed method after reconfiguration. (d) The PV array characteristics for the TCT array and the proposed method. 


\begin{tabular}{|c|c|c|c|c|c|c|c|c|c|}
\hline 11 & 12 & 13 & 14 & 15 & 16 & 17 & 18 & 19 & 110 \\
\hline 21 & 22 & 23 & 24 & 25 & 26 & 27 & 28 & 29 & 210 \\
\hline 31 & 32 & 33 & 34 & 35 & 36 & 37 & 38 & 39 & 310 \\
\hline 41 & 42 & 43 & 44 & 45 & 46 & 47 & 48 & 49 & 410 \\
\hline 51 & 52 & 53 & 54 & 55 & 56 & 57 & 58 & 59 & 510 \\
\hline 61 & 62 & 63 & 64 & 65 & 66 & 67 & 68 & 69 & 610 \\
\hline 71 & 72 & 73 & 74 & 75 & 76 & 77 & 78 & 79 & 710 \\
\hline 81 & 82 & 83 & 84 & 85 & 86 & 87 & 88 & 89 & 810 \\
\hline 91 & 92 & 93 & 94 & 95 & 96 & 97 & 98 & 99 & 910 \\
\hline 101 & 102 & 103 & 104 & 105 & 106 & 107 & 108 & 109 & 1010 \\
\hline
\end{tabular}

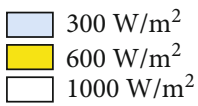

(a) \begin{tabular}{|l|l|l|l|l|}
\hline 11 & 42 & 23 & 54 & 35 \\
\hline 21 & 52 & 33 & 14 & 45 \\
\hline
\end{tabular} \begin{tabular}{|l|l|l|l|l|}
\hline 21 & 52 & 33 & 14 & 45 \\
\hline 31 & 12 & 43 & 24 & 55 \\
\hline
\end{tabular}

\begin{tabular}{|l|l|l|l|l|}
\hline 31 & 12 & 43 & 24 & 55 \\
\hline 41 & 22 & 53 & 34 & 15 \\
\hline
\end{tabular}

\begin{tabular}{llllll}
41 & 22 & 53 & 34 & 15 \\
\hline 5 & 3 & 13 & 44 & 25 \\
\hline
\end{tabular} \begin{tabular}{|l|l|l|l|l|}
\hline 51 & 32 & 13 & 44 & 25 \\
\hline
\end{tabular}

\begin{tabular}{|l|l|l|l|l|}
\hline 11 & 42 & 23 & 54 & 35 \\
\hline
\end{tabular} \begin{tabular}{|l|l|l|l|l|}
\hline 1 & 42 & 23 & 54 & 35 \\
\hline 21 & 52 & 33 & 14 & 45 \\
\hline 31 & 12 & 43 & 24 & 55 \\
\hline
\end{tabular} \begin{tabular}{lllllll}
\hline 31 & 12 & 43 & 24 & 55 \\
\hline 4 & 2 & 53 & 34 & 15 \\
\hline
\end{tabular}

\begin{tabular}{|l|l|l|l|l|}
\hline 41 & 22 & 53 & 34 & 15 \\
\hline 51 & 32 & 13 & 44 & 25 \\
\hline
\end{tabular} \begin{tabular}{|l|l|l|l|l|}
\hline 51 & 32 & 13 & 44 & 25 \\
\hline
\end{tabular}

\section{$\square 300 \mathrm{~W} / \mathrm{m}^{2}$} $600 \mathrm{~W} / \mathrm{m}^{2}$ $1000 \mathrm{~W} / \mathrm{m}^{2}$ \begin{tabular}{|l|l|l|l|l|}
\hline 11 & 42 & 23 & 54 & 35 \\
\hline
\end{tabular}

\begin{tabular}{|l|l|l|l|l|}
\hline 21 & 52 & 33 & 14 & 45 \\
\hline
\end{tabular}

\begin{tabular}{|l|l|l|l|l|}
\hline 31 & 12 & 43 & 24 & 55 \\
\hline 41 & 22 & 53 & 34 & 15 \\
\hline
\end{tabular}

\begin{tabular}{|l|l|l|l|l|}
\hline 41 & 22 & 53 & 34 & 15 \\
\hline
\end{tabular}

\begin{tabular}{|l|l|l|l|l|}
\hline 51 & 32 & 13 & 44 & 25 \\
\hline
\end{tabular}

\begin{tabular}{|l|l|l|l|l|}
\hline 11 & 42 & 23 & 54 & 35 \\
\hline
\end{tabular}

\begin{tabular}{|l|l|l|l|l|l|}
\hline 21 & 52 & 33 & 14 & 45 \\
\hline
\end{tabular}

\begin{tabular}{lll|l|l|l|}
31 & 12 & 43 & 24 & 55 \\
\hline
\end{tabular}

\begin{tabular}{|l|l|l|l|l|}
\hline 41 & 12 & 43 & 24 & 55 \\
\hline 41 & 22 & 53 & 34 & 15 \\
\hline 51 & 32 & 13 & 44 & 25 \\
\hline
\end{tabular}

\begin{tabular}{|l|l|l|l|l|}
\hline 51 & 32 & 13 & 44 & 25 \\
\hline
\end{tabular}

(b)

\begin{tabular}{|l|l|l|l|l|}
\hline 11 & 12 & 13 & 14 & 15 \\
\hline 21 & 22 & 23 & 24 & 25 \\
\hline 31 & 32 & 33 & 34 & 35 \\
\hline 41 & 42 & 43 & 44 & 45 \\
\hline 51 & 52 & 53 & 54 & 55 \\
\hline 11 & 12 & 13 & 14 & 15 \\
\hline 21 & 22 & 23 & 24 & 25 \\
\hline 31 & 32 & 33 & 34 & 35 \\
\hline 41 & 42 & 43 & 44 & 45 \\
\hline 51 & 52 & 53 & 54 & 55 \\
\hline 11 & 12 & 13 & 14 & 15 \\
\hline 21 & 22 & 23 & 24 & 25 \\
\hline 31 & 32 & 33 & 34 & 35 \\
\hline 41 & 42 & 43 & 44 & 45 \\
\hline 51 & 52 & 53 & 54 & 55 \\
\hline 11 & 12 & 13 & 14 & 15 \\
\hline 21 & 22 & 23 & 24 & 25 \\
\hline 31 & 32 & 33 & 34 & 35 \\
\hline 41 & 42 & 43 & 44 & 45 \\
\hline 51 & 52 & 53 & 54 & 55 \\
\hline
\end{tabular}

(c)

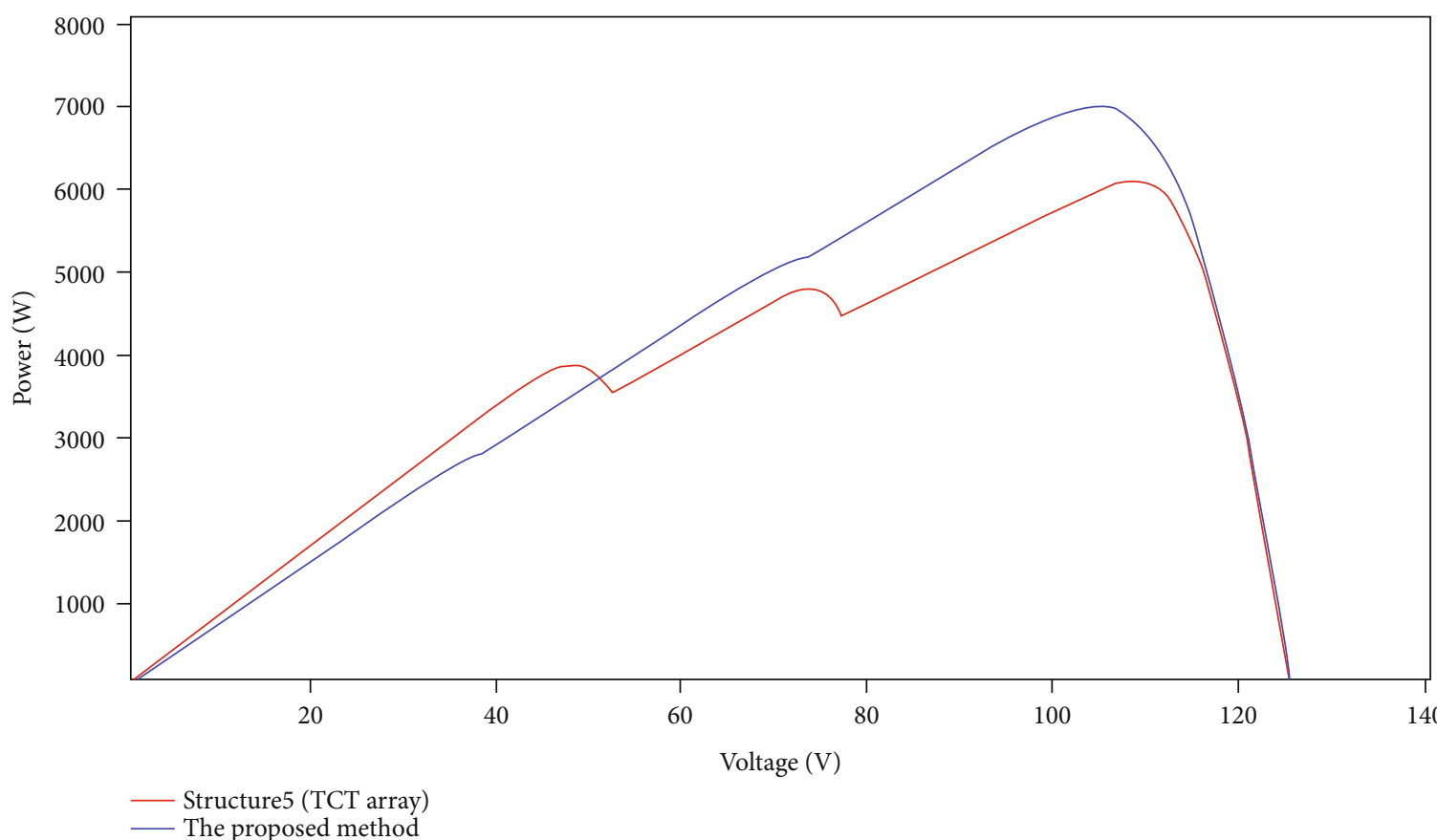

(d)

Figure 17: Eighth shading pattern. (a) TCT array. (b) The proposed method before reconfiguration. (c) The proposed method after reconfiguration. (d) The PV array characteristics for the TCT array and the proposed method.

$5 \times 5$ TCT subarrays, and connections of subarrays are again in the form of a TCT array, which alters dynamically. In the third structure, a hundred modules are divided into four 5 $\times 5$ TCT subarrays with wiring in static reconfiguration, and connections of subarrays are in the form of a TCT array. In the fourth structure, which is to verify the proposed method, a hundred modules are divided into four $5 \times 5$ TCT subarrays with wiring in static reconfiguration, and 


\begin{tabular}{|c|c|c|c|c|c|c|c|c|c|}
\hline \multicolumn{5}{|c|}{1} & \multicolumn{5}{|c|}{2} \\
\hline 11 & 12 & 13 & 14 & 15 & 11 & 12 & 13 & 14 & 15 \\
\hline 21 & 22 & 23 & 24 & 25 & 21 & 22 & 23 & 24 & 25 \\
\hline 31 & 32 & 33 & 34 & 35 & 31 & 32 & 33 & 34 & 35 \\
\hline 41 & 42 & 43 & 44 & 45 & 41 & 42 & 43 & 44 & 45 \\
\hline 51 & 52 & 53 & 54 & 55 & 51 & 52 & 53 & 54 & 55 \\
\hline \multicolumn{5}{|c|}{3} & \multicolumn{5}{|c|}{4} \\
\hline 11 & 12 & 13 & 14 & 15 & 11 & 12 & 13 & 14 & 15 \\
\hline 21 & 22 & 23 & 24 & 25 & 21 & 22 & 23 & 24 & 25 \\
\hline 31 & 32 & 33 & 34 & 35 & 31 & 32 & 33 & 34 & 35 \\
\hline 41 & 42 & 43 & 44 & 45 & 41 & 42 & 43 & 44 & 45 \\
\hline 51 & 52 & 53 & 54 & 55 & 51 & 52 & 53 & 54 & 55 \\
\hline
\end{tabular}

FIGURE 18: Fifth shading pattern (after applying static reconfiguration).

TABLE 2: Different connections for power enhancement.

\begin{tabular}{lcccc}
\hline Different connections & $I_{\max }$ & $I_{\min }$ & $G_{\mathrm{MPP}}$ & CEI \\
\hline $12-34$ & $86.4 \mathrm{~A}$ & $64.798 \mathrm{~A}$ & $6667 \mathrm{~W}$ & 21.602 \\
$13-24$ & $79.488 \mathrm{~A}$ & $70.848 \mathrm{~A}$ & $7003 \mathrm{~W}$ & 8.62 \\
$14-23$ & $79.488 \mathrm{~A}$ & $68.256 \mathrm{~A}$ & $6964 \mathrm{~W}$ & 11.232 \\
\hline
\end{tabular}

connections are in the form of a TCT array, which alters dynamically. In the fifth structure, a hundred modules are wired in the form of a $10 \times 10$ TCT array. In the sixth and final structure, a hundred modules are wired as static reconfiguration. The results of the proposed method (from the fourth structure) are compared to others.

Shadows occurring in the PV array can be modeled using two indicators: (i) shading intensity and (ii) shading shape. The shading intensity is measured in watts per square meter $\left(\mathrm{W} / \mathrm{m}^{2}\right)$ and denotes the amount of irradiance over the modules that a shadow can filter. The shape of the shadow is determined by the number of shaded strings (width) and modules per string (length) [29]. As illustrated in Figure 9, (a) short and narrow, (b) short and wide, (c) long and narrow, and (d) long and wide are four different types of shading patterns that can occur on a PV array. Among these, short and narrow and short and wide shading patterns are repetitive, and long and wide engages a relatively large percentage of the PV array.

In this paper, four different types of shading patterns (i.e., short and narrow, short and wide, long and narrow, and long and wide) with irradiation profiles of $300 \mathrm{~W} / \mathrm{m}^{2}$ and $600 \mathrm{~W} / \mathrm{m}^{2}$ are applied to two subarrays in the first to fourth structures. In addition, three shading patterns, which are a combination of these shadows with short and narrow shading patterns, are applied to four subarrays. Further, a diagonal shading pattern is applied to two subarrays. Also, shading patterns with the same size and irradiation profile are applied to the fifth and sixth structures. Figures 10-17 show the eight shading patterns applied to the proposed structure and the $10 \times 10$ TCT array as well as the PV array characteristics.

4.1. Identifying Optimal Connections. For dynamic reconfiguration, the controller employs the introduced algorithm to search for all the possible connections in the form of a TCT array and finally identifies the most optimal solution, which enhances the output power. The fifth shading pattern (after applying static reconfiguration) is shown in Figure 18. The numbers allocated to each subarray are subarray numbers. In addition, different connections capable of enhancing the output power are presented in Table 2 as " $x y-w z$," in which " $x y$ " and " $w z$ " denote the subarrays in the first and second rows, respectively. It is obvious that $12-34,21-34$, and $34-$ 12 are the same connections since either the parallel location in the first row or the series location in the second row has been altered. Based on this table, the 13-24 connection is optimal as it offers the smallest amount for the CEI index. In fact, this index ensures that the proposed method meets the global maximum power in addition to offering the lowest difference between the total currents of subarray rows. As a result, smoother $P-V$ characteristics are achieved and a simpler strategy for MPP tracking is required.

4.2. Performance Parameter Analysis. To verify the overall performance enhancement attained with the proposed method, a comprehensive comparison is made between the proposed method and other structures in terms of performance parameters such as (a) mismatch power loss, (b) percentage power loss, and (c) percentage power enhancement [24].

4.2.1. Mismatch Power Loss. The mismatch loss typically occurs when the PV modules do not operate at their maximum power point. Thus, the difference between two points such as the maximum power without partial shading condition $P_{\max \text { _unshaded }}$ and the maximum probable power under partial shading condition $P_{G_{\mathrm{MPP}}}$ are regarded as mismatch power loss and can be calculated as

$$
P_{\text {mismatch loss }}=P_{\text {max _unshaded }}-P_{G_{\mathrm{MPP}}} \text {. }
$$

4.2.2. Percentage Power Loss. The occurrence of multiple peaks is one of the leading causes of power loss. The percentage power loss is defined as the ratio of the difference in global maximum power at standard test condition (STC) and partial shading condition (PSC) to the global maximum power at STC of the array and is given by

$$
\% \text { power loss }=\frac{G_{\text {MPP_STC }}-G_{\text {MPP_PSC }}}{G_{\text {MPP_STC }}} \times 100 .
$$

4.2.3. Percentage Power Enhancement. The total power difference between the conventional value and the proposed value at the global power peak is known as percentage power enhancement and is computed as

\%power enhancement $=\frac{G_{\mathrm{MPP}_{\text {propsed method }}}-G_{\mathrm{MPP}_{\text {conventional }}}}{G_{\text {conventional }}} \times 100$.

4.3. Comparing to Other Structures. Table 3 provides a comparison between the proposed method and other structures 
TABLE 3: Estimation of performance indices for shading patterns 1-8.

\begin{tabular}{|c|c|c|c|c|c|c|}
\hline Configuration & & Voltage (V) & Current (I) & Power generation $(\mathrm{W})$ & Mismatch loss (W) & Power loss (\%) \\
\hline \multirow{6}{*}{ Shading pattern 1} & Structure 1 & 108.7 & 65.78 & 7148 & 1175 & 14.11 \\
\hline & Structure 2 & 104.8 & 72.52 & 7603 & 720 & 8.65 \\
\hline & Structure 3 & 106 & 72.24 & 7658 & 665 & 7.98 \\
\hline & The proposed method & 103.8 & 75.8 & 7879 & 444 & 5.33 \\
\hline & Structure 5 & 108.9 & 65.64 & 7148 & 1175 & 14.11 \\
\hline & Structure 6 & 106.3 & 72.65 & 7719 & 604 & 7.25 \\
\hline \multirow{6}{*}{ Shading pattern 2} & Structure 1 & 81.9 & 79.87 & 6542 & 1781 & 21.39 \\
\hline & Structure 2 & 81.9 & 79.87 & 6542 & 1781 & 21.39 \\
\hline & Structure 3 & 108.8 & 60.92 & 6632 & 1691 & 20.31 \\
\hline & The proposed method & 105 & 69.78 & 7355 & 968 & 11.63 \\
\hline & Structure 5 & 82.1 & 79.8 & 6542 & 1781 & 21.39 \\
\hline & Structure 6 & 103.9 & 70.78 & 7355 & 968 & 11.63 \\
\hline \multirow{6}{*}{ Shading pattern 3} & Structure 1 & 108.7 & 60.31 & 6555 & 1768 & 21.24 \\
\hline & Structure 2 & 104.2 & 69.9 & 7284 & 1039 & 12.48 \\
\hline & Structure 3 & 108.7 & 60.93 & 6620 & 1703 & 20.46 \\
\hline & The proposed method & 104.3 & 70.17 & 7319 & 1004 & 12.06 \\
\hline & Structure 5 & 106.3 & 64.54 & 6860 & 1463 & 17.58 \\
\hline & Structure 6 & 105.4 & 68.86 & 7239 & 1084 & 13.02 \\
\hline \multirow{6}{*}{ Shading pattern 4} & Structure 1 & 85.45 & 54.11 & 4731 & 3592 & 43.15 \\
\hline & Structure 2 & 105.1 & 57.44 & 6034 & 2289 & 27.5 \\
\hline & Structure 3 & 111.2 & 45.5 & 4948 & 3375 & 40.55 \\
\hline & The proposed method & 104.8 & 61.56 & 6454 & 1869 & 22.45 \\
\hline & Structure 5 & 85.6 & 54.01 & 4731 & 3592 & 43.15 \\
\hline & Structure 6 & 106.6 & 75.79 & 6410 & 1913 & 22.98 \\
\hline \multirow{6}{*}{ Shading pattern 5} & Structure 1 & 84.8 & 67.86 & 5754 & 2569 & 30.86 \\
\hline & Structure 2 & 84.8 & 67.86 & 5754 & 2569 & 30.86 \\
\hline & Structure 3 & 106.9 & 62.36 & 6667 & 1656 & 19.89 \\
\hline & The proposed method & 103.8 & 67.4 & 7003 & 1320 & 15.85 \\
\hline & Structure 5 & 84.6 & 68.03 & 5753 & 2570 & 30.87 \\
\hline & Structure 6 & 107.3 & 78.7 & 6801 & 1519 & 18.28 \\
\hline \multirow{6}{*}{ Shading pattern 6} & Structure 1 & 107.3 & 60.23 & 6463 & 1860 & 22.34 \\
\hline & Structure 2 & 106.3 & 62.04 & 6592 & 1731 & 20.79 \\
\hline & Structure 3 & 107.7 & 60.8 & 6553 & 1766 & 21.26 \\
\hline & The proposed method & 104 & 65.69 & 6923 & 1400 & 16.82 \\
\hline & Structure 5 & 105.3 & 63.6 & 6703 & 1620 & 19.46 \\
\hline & Structure 6 & 106.7 & 63.25 & 6752 & 1571 & 18.87 \\
\hline \multirow{6}{*}{ Shading pattern 7} & Structure 1 & 86.5 & 54.07 & 4674 & 3649 & 43.84 \\
\hline & Structure 2 & 109.8 & 48.93 & 5399 & 2924 & 35.1 \\
\hline & Structure 3 & 110.7 & 44.88 & 4921 & 3402 & 40.8 \\
\hline & The proposed method & 106.2 & 56.7 & 6020 & 2303 & 27.6 \\
\hline & Structure 5 & 86.7 & 53.91 & 4674 & 3649 & 43.8 \\
\hline & Structure 6 & 108.1 & 54.09 & 5848 & 2475 & 29.7 \\
\hline \multirow{6}{*}{ Shading pattern 8} & Structure 1 & 112 & 48.99 & 5487 & 2836 & 34.07 \\
\hline & Structure 2 & 105.4 & 63.93 & 6736 & 1587 & 19.06 \\
\hline & Structure 3 & 110.2 & 53.99 & 5950 & 2373 & 28.51 \\
\hline & The proposed method & 104.9 & 66.58 & 6985 & 1338 & 16.07 \\
\hline & Structure 5 & 108.7 & 56.1 & 6099 & 2224 & 26.72 \\
\hline & Structure 6 & 108.7 & 61.04 & 6636 & 1687 & 20.26 \\
\hline
\end{tabular}


TABle 4: Power enhancement for shading patterns 1-8.

\begin{tabular}{|c|c|c|}
\hline Shading pattern & Structures & Power enhancement (\%) \\
\hline \multirow{5}{*}{ Shading pattern 1} & Structure 1 & 10.22 \\
\hline & Structure 2 & 3.63 \\
\hline & Structure 3 & 2.88 \\
\hline & Structure 5 & 10.22 \\
\hline & Structure 6 & 2.07 \\
\hline \multirow{5}{*}{ Shading pattern 2} & Structure 1 & 12.42 \\
\hline & Structure 2 & 12.42 \\
\hline & Structure 3 & 10.83 \\
\hline & Structure 5 & 12.42 \\
\hline & Structure 6 & 0 \\
\hline \multirow{5}{*}{ Shading pattern 3} & Structure 1 & 11.42 \\
\hline & Structure 2 & 0.48 \\
\hline & Structure 3 & 10.55 \\
\hline & Structure 5 & 6.69 \\
\hline & Structure 6 & 1.1 \\
\hline \multirow{5}{*}{ Shading pattern 4} & Structure 1 & 36.41 \\
\hline & Structure 2 & 6.96 \\
\hline & Structure 3 & 30.43 \\
\hline & Structure 5 & 36.41 \\
\hline & Structure 6 & 0.68 \\
\hline \multirow{5}{*}{ Shading pattern 5} & Structure 1 & 21.7 \\
\hline & Structure 2 & 21.7 \\
\hline & Structure 3 & 5.02 \\
\hline & Structure 5 & 21.72 \\
\hline & Structure 6 & 2.97 \\
\hline \multirow{5}{*}{ Shading pattern 6} & Structure 1 & 7.96 \\
\hline & Structure 2 & 7.11 \\
\hline & Structure 3 & 5.64 \\
\hline & Structure 5 & 3.28 \\
\hline & Structure 6 & 2.53 \\
\hline \multirow{5}{*}{ Shading pattern 7} & Structure 1 & 28.79 \\
\hline & Structure 2 & 11.5 \\
\hline & Structure 3 & 22.33 \\
\hline & Structure 5 & 28.79 \\
\hline & Structure 6 & 2.94 \\
\hline \multirow{5}{*}{ Shading pattern 8} & Structure 1 & 27.3 \\
\hline & Structure 2 & 3.69 \\
\hline & Structure 3 & 17.39 \\
\hline & Structure 5 & 14.52 \\
\hline & Structure 6 & 5.25 \\
\hline
\end{tabular}

in terms of mismatch and power losses as well as the amount of voltage, current, and power under different shading patterns. Also, another comparison in terms of power improvement is made and the results are presented in Table 4 and Figure 19. The global maximum power under shadowless conditions is $8323 \mathrm{~W}$ in all structures. Power losses for the first, second, third, fourth, fifth, and sixth structures are in the range of $14.11-43.84 \%, 8.65-35.1 \%, 7.98-40.55 \%, 5.33-$
$27.6 \%, 14.11-43.8 \%$, and $7.25-29.7 \%$, respectively. As can be seen, the power loss for the proposed method in the fourth structure is the lowest. Furthermore, the global maximum voltage of the proposed method and other structures, as well as the PV diagrams above, shows that the global maximum power point $\left(G_{\mathrm{MPP}}\right)$ is located in the rightmost part of $P-V$ characteristics and the global maximum voltage is very close to the nominal voltage of the PV array. Therefore, the shadows have effectively been dispersed, which in turn results in a smoother $P-V$ curve and reduced bypass diode ON-time. The first structure with no static or dynamic reconfiguration is the simplest structure among the other structures. Despite its simplicity, this structure imposes the highest power losses. Under the third, sixth, and eighth shading patterns, the mismatch losses are 1768, 1860, and $2836 \mathrm{~W}$, respectively. However, the mismatch losses in the fifth structure with the same shading pattern are 1463, 1620 , and $2224 \mathrm{~W}$, respectively. Therefore, the decomposition of the array into subarrays has led to mismatch losses in some shading patterns compared to structure 5. Further, the global maximum voltage value for the second, fourth, fifth, and seventh shading patterns indicates that it is far from the nominal voltage value of the array, which increases the bypass diode ON-time in structure 1. Compared to structure 1 , the maximum power improvement of the proposed method is obtained in the fourth shading pattern (equal to $36.41 \%)$. After dynamic reconfiguration for the first structure, the second structure is formed. Despite lower losses compared to structures 1 and 5, structure 2 still imposes high losses. Additionally, the global maximum voltage value under the second and fifth shading patterns indicates that the global maximum voltage is far from the nominal voltage of the array. Although compared to structures 1 and 5, this voltage deviation is observed in less shading patterns, and it ultimately increases the bypass diode ON-time in structure 2 . Compared to structure 2, the greatest power improvement of the proposed method is gained in the fifth shading pattern (equal to $21.7 \%$ ). After static reconfiguration for the first structure, structure 3 is formed. Despite lower losses compared to structures 1 and 5, structure 3 still imposes high losses. The highest power improvement of the proposed method with regard to this method is gained in the fourth shading pattern $(30.43 \%)$. Structure 5 , which is a $10 \times 10$ TCT array, imposes the largest power losses. Also, the global maximum voltage value in the second, fourth, fifth, and seventh shading patterns is far from its nominal value, which increases the bypass diode ON-time in this structure. Compared to structure 5, the greatest power improvement of the proposed method is attained in the fourth shading pattern (equal to $36.41 \%$ ). Structure 6 is a $10 \times 10$ TCT array with static reconfiguration. Apart from all the benefits mentioned above, the proposed method in the eighth shading pattern has an improvement of $5.25 \%$ compared to structure 6 . In Table 5, the proposed method is compared with the dynamic method in terms of the number of sensors and switches required, where $M$ and $N$ symbolize the number of rows and columns in the dynamic method, respectively. Also, $m$ indicates the number of rows of each subarray in the proposed method and $N_{\mathrm{pv}}$ is the number of subarrays. As can 


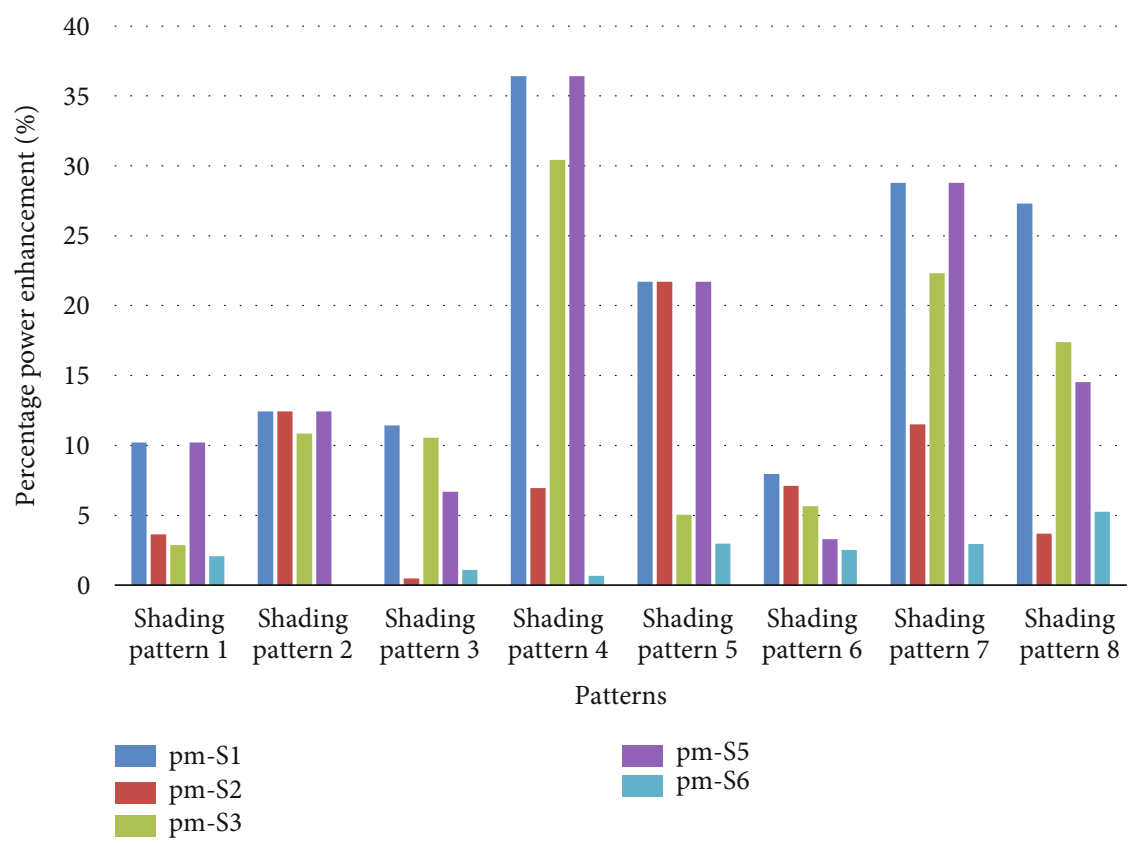

FIgURE 19: Power enhancement of the proposed method and structures 1-6 under different shading patterns.

TABLE 5: Numbers of switches/sensors required in the proposed method and a $10 \times 10$ dynamic reconfiguration.

\begin{tabular}{lccc}
\hline Method & Current sensors & Voltage sensors & Switches \\
\hline Dynamic reconfiguration method in Ref. [11] & $M \times N=100$ & $M \times N=100$ & $2 \times M \times N=200$ \\
The proposed method & $\mathrm{m} \times N_{\mathrm{pv}}=20$ & - & $2 N_{\mathrm{pv}}-2=6$ \\
\hline
\end{tabular}

be seen, the proposed method calls for the least number of switches and sensors.

\section{Future Scope}

Applying the image processing method instead of the shortcircuit current method would be the future of this work. As an advantage, the image processing method eliminates the need for current sensors. To detect shading patterns, PV subarrays are depicted and analyzed at specified intervals.

\section{Conclusion}

In the large-scale PV arrays, static reconfiguration increases wiring and installation complexity in locations with optimal irradiation. On the other hand, dynamic reconfiguration leads to a massive increase in the number of switches and sensors required. To overcome these issues, a two-step method has been proposed in this paper. In the first step, the modules inside the PV array are divided into subarrays with wiring in static reconfiguration instead of being wired in the form of a large-scale PV array. In the second step, an algorithm is introduced for dynamic reconfiguration. The introduced algorithm in the controller searches for all the possible connections and eventually identifies the most optimal one. This algorithm utilizes only short-circuit currents of subarray rows, resulting in a reduced number of sensors and switches required. The effectiveness of the proposed method is verified by simulations for six different structures under eight various shading patterns. While the first structure is the simplest form of the proposed method, the second and third structures are dynamically and statically reconfigured forms of the proposed method, respectively. The fifth and sixth structures also represent the TCT and statically modified TCT arrays, respectively. The results show that the proposed method presents the lowest power losses (in the range of 5.33-27.6) under different shading patterns. Compared to the TCT structure, the second and third dynamically or statically reconfigured structures yield performance improvement, but they still impose losses compared with the statically modified TCT array. Compared to the TCT array, the greatest power improvement of the proposed method is obtained under the fourth shading pattern (equal to 36.41 ). In comparison with the statically modified TCT array, the power improvement of the proposed method under the eighth shading pattern is equal to 5.25.

\section{Data Availability}

Regarding the data availability statement, no data from other sources is used in the paper.

\section{Conflicts of Interest}

The authors declare that they have no conflicts of interest. 


\section{References}

[1] D. T. Cotfas, D. Sera, E. Kaplani, P. A. Cotfas, and A. Rezaniakolaei, "Advancements in photovoltaic cell and system technologies," International Journal of Photoenergy, vol. 2019, 2 pages, 2019.

[2] R. A. Mastromauro, M. Liserre, and A. Dell'Aquila, "Control issues in single-stage photovoltaic systems: MPPT, current and voltage control," IEEE Transactions on Industrial Informatics, vol. 8, no. 2, pp. 241-254, 2012.

[3] Y.-J. Wang and P.-C. Hsu, "Analytical modelling of partial shading and different orientation of photovoltaic modules," IET Renewable Power Generation, vol. 4, no. 3, pp. 272-282, 2010.

[4] L. Gao, R. A. Dougal, S. Liu, and A. P. Iotova, "Parallel-connected solar PV system to address partial and rapidly fluctuating shadow conditions," IEEE Transactions on Industrial Electronics, vol. 56, no. 5, pp. 1548-1556, 2009.

[5] H. Patel and V. Agarwal, "Maximum power point tracking scheme for PV systems operating under partially shaded conditions," IEEE Transactions on Industrial Electronics, vol. 55, no. 4, pp. 1689-1698, 2008.

[6] H. Patel and V. Agarwal, "MATLAB-based modeling to study the effects of partial shading on PV array characteristics," IEEE Transactions on Energy Conversion, vol. 23, no. 1, pp. 302-310, 2008.

[7] P. S. Rao, G. S. Ilango, and C. Nagamani, "Maximum power from PV arrays using a fixed configuration under different shading conditions," IEEE journal of Photovoltaics, vol. 4, no. 2, pp. 679-686, 2014.

[8] O. Bingöl and B. Özkaya, "Analysis and comparison of different PV array configurations under partial shading conditions," Solar Energy, vol. 160, pp. 336-343, 2018.

[9] P. R. Satpathy, S. Jena, and R. Sharma, "Power enhancement from partially shaded modules of solar PV arrays through various interconnections among modules," Energy, vol. 144, pp. 839-850, 2018.

[10] G. S. Krishna and T. Moger, "Reconfiguration strategies for reducing partial shading effects in photovoltaic arrays: state of the art," Solar Energy, vol. 182, pp. 429-452, 2019.

[11] G. Velasco Quesada, F. Guinjoan Gispert, R. Piqué-López, M. Roman Lumbreras, and A. Conesa Roca, "Electrical PV array reconfiguration strategy for energy extraction improvement in grid connected PV systems," IEEE Transactions on Industrial Electronics, vol. 56, no. 11, pp. 4319-4331, 2009.

[12] K. S. Parlak, "PV array reconfiguration method under partial shading conditions," International Journal of Electrical Power and Energy Systems, vol. 63, pp. 713-721, 2014

[13] S. N. Deshkar, S. B. Dhale, J. S. Mukherjee, T. S. Babu, and N. Rajasekar, "Solar PV array reconfiguration under partial shading conditions for maximum power extraction using genetic algorithm," Renewable and Sustainable Energy Reviews, vol. 43, pp. 102-110, 2015.

[14] T. S. Babu, J. P. Ram, T. Dragičević, M. Miyatake, F. Blaabjerg, and N. Rajasekar, "Particle swarm optimization based solar PV array reconfiguration of the maximum power extraction under partial shading conditions," IEEE Transactions on Sustainable Energy, vol. 9, no. 1, pp. 74-85, 2017.

[15] Y. Mahmoud and E. F. Saadany, "Enhanced reconfiguration method for reducing mismatch losses in PV systems," IEEE Journal of Photovoltaics, vol. 7, no. 6, pp. 1746-1754, 2017.
[16] M. Karakose and M. Baygin, "Image processing-based analysis of moving shadow effects for reconfiguration in PV arrays," in IEEE International Energy Conference, pp. 683-687, Cavtat, Croatia, 2014.

[17] M. Jazayeri, K. Jazayeri, and S. Uysal, “Adaptive photovoltaic array reconfiguration based on real cloud patterns to mitigate effects of non-uniform spatial irradiance profiles," Solar Energy, vol. 155, pp. 506-516, 2017.

[18] S. Malathy and R. Ramaprabha, "Reconfiguration strategies to extract maximum power from photovoltaic array under partially shaded conditions," Renewable and Sustainable Energy Reviews, vol. 81, pp. 2922-2934, 2018.

[19] B. I. Rani, G. S. Ilango, and C. Nagamani, "Enhanced power generation from PV array under partial shading conditions by shade dispersion using Su Do Ku configuration," IEEE Transactions on Sustainable Energy, vol. 4, no. 3, pp. 594601, 2013.

[20] S. R. Potnuru, D. Pattabiraman, S. I. Ganesan, and N. Chilakapati, "Positioning of PV panels for reduction in line losses and mismatch losses in PV array," Renewable Energy, vol. 78, pp. 264-275, 2015.

[21] M. Horoufiany and R. Ghandehari, "Optimization of the Sudoku based reconfiguration technique for PV arrays power enhancement under mutual shading conditions," Solar Energy, vol. 159, pp. 1037-1046, 2018.

[22] H. S. Sahu, S. K. Nayakand, and S. Mishra, "Maximizing the power generation of a partially shaded PV array," IEEE journal of emerging and selected topics in power electronics, vol. 4, no. 2, pp. 626-637, 2015.

[23] B. Dhanalakshmi and N. Rajasekar, "Dominance square-based array reconfiguration scheme for power loss reduction in solar photovoltaic (PV) systems," Energy conversion and management, vol. 156, pp. 84-102, 2018.

[24] B. Dhanalakshmi and N. Rajasekar, "A novel competence square based PV array reconfiguration technique for solar PV maximum power extraction," Energy Conversion and Management, vol. 174, pp. 897-912, 2018.

[25] P. R. Satpathy, R. Sharma, and S. Dash, “An efficient SD-PAR technique for maximum power generation from modules of partially shaded PV arrays," Energy, vol. 175, pp. 182-194, 2019.

[26] M. S. S. Nihanth, J. P. Ram, D. S. Pillai, A. M. Ghias, A. Garg, and N. Rajasekar, "Enhanced power production in PV arrays using a new skyscraper puzzle based one-time reconfiguration procedure under partial shade conditions (PSCs)," Solar Energy, vol. 194, pp. 209-224, 2019.

[27] R. Venkateswari and N. Rajasekar, "Power enhancement of PV system via physical array reconfiguration based Lo Shu technique," Energy Conversion and Management, vol. 215, article 112885, 2020.

[28] H. Can, D. Ickilli, and K. S. Parlak, "A new numerical solution approach for the real-time modeling of photovoltaic panels," in Asia-Pacific Power and Energy Engineering Conference, pp. 1-4, Shanghai, China, 2012.

[29] L. F. L. Villa, D. Picault, B. Raison, S. Bacha, and A. Labonne, "Maximizing the power output of partially shaded photovoltaic plants through optimization of the interconnections among its modules," IEEE Journal of Photovoltaics, vol. 2, no. 2, pp. 154-163, 2012. 